OPEN ACCESS

Edited by:

Abhay K. Pandey,

Tockali Tea Research Institute,

TRA, India

Reviewed by:

Guadalupe Virginia Nevárez-Moorillón,

Autonomous University of

Chihuahua, Mexico

Zinash A. Belay,

Agricultural Research Council of South

Africa (ARC-SA), South Africa

*Correspondence:

Kalidas Shetty

kalidas.shetty@ndsu.edu

Specialty section:

This article was submitted to

Sustainable Food Processing,

a section of the journal

Frontiers in Sustainable Food Systems

Received: 30 April 2021

Accepted: 05 July 2021

Published: 29 July 2021

Citation:

Pucel N, Sarkar D, Labbe RG,

Khanongnuch $C$ and Shetty K (2021)

Improving Health Targeted Food

Quality of Blackberry: Pear Fruit

Synergy Using Lactic Acid Bacterial

Fermentation

Front. Sustain. Food Syst. 5:703672.

doi: 10.3389/fsufs.2021.703672

\section{Improving Health Targeted Food Quality of Blackberry: Pear Fruit Synergy Using Lactic Acid Bacterial Fermentation}

\author{
Nicholas Pucel ${ }^{1}$, Dipayan Sarkar ${ }^{1,2}$, Ronald G. Labbe ${ }^{1}$, Chartchai Khanongnuch ${ }^{3}$ and \\ Kalidas Shetty ${ }^{1,2 *}$ \\ ${ }^{1}$ Department of Food Science, University of Massachusetts, Amherst, MA, United States, ${ }^{2}$ Department of Plant Sciences, \\ North Dakota State University, Fargo, ND, United States, ${ }^{3}$ Division of Biotechnology, School of Agro-Industry, Chiang Mai \\ University, Chiang Mai, Thailand
}

Blackberry and pear are rich in human health protective phenolic bioactives with high antioxidant activity. These fruits are relevant dietary targets to counter chronic oxidative stress-linked diseases, such as type 2 diabetes (T2D). Due to high perishability, the human health relevant bioactive qualities of such fruits deteriorate during postharvest storage and processing. By improving stability and bioavailability of nutritionally relevant phenolic bioactives during post-harvest stages, effective integration of blackberry and pear as dietary support strategies can be targeted for T2D benefits. Solutions to bioactive quality loss of fruits can be achieved by advancing bioprocessing strategy integrating compatible fruit synergy and beneficial lactic acid bacteria (LAB) based fermentation. This approach was targeted to enhance high levels of phenolic bioactive-linked health quality of blackberry (Rubus spp.) integrated with pear (Pyrus communis) at a ratio of 30:70, which was optimized previously based on potential synergistic effects. The aim of this study was to recruit beneficial LAB such as Lactobacillus helveticus and Bifidobacterium longum to bioprocess previously optimized blackberry: pear synergies to improve phenolic bioactive-linked T2D benefits. Essential health-targeted food quality during bioprocessing was assessed based on total soluble phenolic content, phenolic compound profile, total antioxidant activity, anti-hyperglycemic property relevant $\alpha$-amylase and $\alpha$-glucosidase enzyme inhibitory, and anti-hypertensive relevant angiotensin-l-converting enzyme (ACE) inhibitory activities using in vitro assay models. Additionally, potential inhibitory activity of fermented fruit extracts against pathogenic Helicobacter pylori, the common bacterial ulcer pathogen was also investigated. Overall, improvement in the retention and stability of phenolic bioactive content in 30:70 blackberry: pear combination, as well as in $100 \%$ juice of both fruit extracts were observed following fermentation. Furthermore, enhanced antioxidant activity, anti-hyperglycemic property relevant $\alpha$-glucosidase, and anti-hypertensive property relevant ACE enzyme inhibitory activities were also observed in fermented extracts of 30:70 blackberry: pear synergy. Among the substrates only fermentation of 100\% blackberry 
with $L A B$ resulted in inhibitory activity against $H$. pylori. These results provide the biochemical rationale to develop blackberry: pear fruit synergy and beneficial LAB-based fermentation to improve T2D relevant health benefits while also potentially improving keeping quality.

Keywords: antioxidant, anti-hyperglycemic, fermentation, fruit synergy, gut health, phenolic bioactives

\section{INTRODUCTION}

Fruits and vegetables containing rich antioxidant profile are excellent dietary sources to counter chronic oxidative stress induced metabolic breakdowns and associated diseases in humans (Bacchetti et al., 2019). Chronic oxidative stress is one of the key risk factors associated with etiology and pathogenesis of several diet and lifestyle-influenced non-communicable diseases (NCDs), such as type 2 diabetes, cardiovascular diseases, dyslipidemia and cancer (Nediani and Giovannelli, 2020). Therefore, improving diversity and consumption (7-9 serving sizes) of antioxidant rich fruits and vegetables in daily diet is recommended to address oxidative stress induced metabolic breakdowns, which concurrently could support prevention and management of common NCDs (Darfour-Oduro et al., 2018). Not only just oxidative stress protective function, but fruits and vegetables with rich phenolic antioxidant profile also have wider NCD-preventive health benefits like improving glucose metabolism, anti-hypertensive and cardio-protective functions, and human gut health benefits (Sarkar and Shetty, 2014; Satija and $\mathrm{Hu}, 2018$; Xiao and Bai, 2019).

Among healthy diversity of fruits in daily diet, berries are rich sources of dietary antioxidants and health protective bioactives like phenolic (Skrovankova et al., 2015). However, most fruits including pears and berries are highly perishable and their functional and human health protective qualities like antioxidant properties deteriorate rapidly at post-harvest storage and processing stages (Michalska and Łysiak, 2015). Therefore, it is essential to advance bioprocessing strategies to reduce postharvest losses of health relevant fruits in order to improve their access to the consumers. Specifically, higher retention of human health protective phenolic antioxidants and associated functionalities at post-harvest stages is important for designing fruit-based functional foods and beverages targeting wider NCDlinked health benefits (Shetty and Wahlqvist, 2004; Sarkar and Shetty, 2014).

Previously, we observed higher phenolic bioactive-linked antioxidant, and anti-hyperglycemic properties in several berries, relevant for integrating them toward dietary support strategies targeting early stages of type 2 diabetes benefits (Cheplick et al., 2007, 2010, 2015; da Silva Pinto et al., 2008; Sarkar et al., 2016, 2017). Among common berries, production and marketing of blackberry as fresh and processed fruit is growing rapidly in the United States due to higher consumer preferences based on their unique flavor profile and wider perception about potential health benefits (Liao et al., 2020). However, the phenolic bioactive profile and associated human health relevant qualities of blackberry vary widely between cultivars, different maturity stages, due to growing environment and cultivation practices, and based on post-harvest storage and processing conditions (de Souza et al., 2015; Sarkar et al., 2016; Cheplick et al., 2017; Espe et al., 2019a,b; Huynh et al., 2019). Therefore, it is important to advance and optimize post-harvest processing strategies for improving retention of phenolic bioactive-linked antioxidant, anti-hyperglycemic, and anti-hypertensive functionalities in blackberry-based foods and beverages targeting early stages of type 2 diabetes benefits.

Integrating health-targeted and compatible fruits with complementary bioactive profile and health benefits is an effective approach to enhance human health relevant qualities in berry derived processed foods and beverages. Food and beverage industries are currently targeting such strategy of combining other fruits with berry juice and extracts to widen flavor and taste profiles, responding to consumer demands and achieving market advantages. Additionally, integration of compatible fruits based on their specific bioactive-linked functional properties can also enhance human health related qualities in berry-based foods and beverages through potential synergistic or additive effects (Agustinah et al., 2016). Previously, high phenolic bioactive associated antioxidant, anti-hyperglycemic property relevant $\alpha$-amylase and $\alpha$-glucosidase, and anti-hypertensive property relevant angiotensin-I-converting enzyme inhibitory activities were observed in aqueous extracts of pear (cv. Bartlett) (Barbosa et al., 2013; Sarkar et al., 2015). Similarly, high antioxidant and anti-hyperglycemic properties relevant for targeting early stages of type 2 diabetes prevention were also observed in blackberry (cv. Kiowa) (Sarkar et al., 2016). Based on such complimentary health benefits and to achieve wider antioxidant protection relevant for both human health benefits and improving keeping quality, we targeted blackberry (cv. Kiowa): pear (cv. Bartlett) fruit synergy. Such fruit synergy also has potential to improve early stages of type 2 diabetes relevant functional properties to advance health-focused beverage design strategy. In the initial optimization study, higher phenolic-linked antioxidant, antihyperglycemic, and anti-hypertensive properties were observed in 30:70 blackberry: pear combination (Warner, 2012). In the current study, we targeted such optimized 30:70 blackberry: pear combination and pure blackberry and pear extracts $(100 \%)$ and recruited beneficial lactic acid bacteria (LAB) based fermentation strategy to further enhance phenolic-linked functional properties with potential anti-diabetic benefits.

Lactic acid bacteria (LAB) have long been used in ethnic and traditional foods to preserve dairy and plant-based food substrates and prevent spoilage since before constant refrigeration was possible (Lynch et al., 2018). Investigating one-step further than spoilage prevention would be to examine 
the change of certain health relevant quality and benefits of the fermented fruit-based foods and beverages. To achieve this objective, beneficial probiotic bacteria like Lactobacillus helveticus and Bifidobacterium longum were utilized to improve retention and stability of phenolic bioactives of blackberry: pear fruit substrates and subsequently enhancing their antioxidant, anti-hyperglycemic, anti-hypertensive, and anti-bacterial properties. Previously, improvement in antioxidant and anti-hyperglycemic properties of several health-targeted fruit substrates due to improved solubilization and mobilization of free and bound phenolic compounds following LAB based fermentation were observed (Ankolekar et al., 2011, 2012a,b; Fujita et al., 2017; Kaprasob et al., 2017, 2019). The preservation of stability of bioactive phenolics over time in LAB fermented fruit substrates is also relevant to enhance the shelf-life and keeping quality of the food and beverage products. This preservation technique could also be utilized to repurpose fruits that may not be consumed before their expiration, which would increase economic value and decrease losses due to post-harvest spoilage.

Therefore, the major aim of this study was to advance bioprocessing strategies for dual functional benefits by integrating fruit synergy and LAB based fermentation to enhance human health relevant bioactives and post-harvest preservation qualities of blackberry and pear and their fruit synergy. Previously, optimized (Warner, 2012) fruit synergy of blackberry: pear (30:70) combination and 100\% extracts of blackberry and pear were fermented for $48 \mathrm{~h}$ using two different LAB (L. helveticus and B. longum) and total soluble phenolic content, phenolic profile, antioxidant activity, antihyperglycemic, and anti-hypertensive properties of fermented fruit substrates at 0,24 , and $48 \mathrm{~h}$ time points were determined using rapid in vitro assay models. Additionally, potential antibacterial property of LAB fermented fruit substrates against ulcer causing bacteria Helicobacter pylori was also investigated using an agar diffusion assay. Inhibition of $H$. pylori was a secondary objective in the study, but positive results would prove to be an additional value to the health relevant beneficial fruit synergy substrates. The wider goal was to find effective bioprocessing approach by integrating compatible fruit synergy and LAB-based fermentation for improving human health relevant and postharvest preservation qualities of fruit combination derived foods and beverages.

\section{MATERIALS AND METHODS}

\section{Materials}

The enzymes, $\alpha$-glucosidase from yeast $S$. cerevisiae (EC 3.2.1.20), porcine pancreatic $\alpha$-amylase (EC 3.2.1.1) and angiotensin1-converting enzyme from rabbit lung (EC 3.4.15.1) were purchased from Sigma Chemical Co. (St. Louis, MO, USA). Unless noted, all chemicals were also purchased from Sigma Chemical Co. (St. Louis, MO, USA).

The pear (cv. Bartlett) was sourced from a local Big Y supermarket (Hadley, MA, USA), while the blackberry (cv. Kiowa) were obtained from the Auburn University (Auburn, AL, USA) and stored in freezer $\left(-40^{\circ} \mathrm{C}\right)$ before fruit extractions and fermentation. The fruits were transported in Cooler (zip lock bags) with ice packs to maintain freezing condition.

\section{Sample Preparation}

Fresh Bartlett pears were homogenized in a Waring blender (Waring Commercial Kitchen Appliances, CA, USA) for 3 min after which the supernatant was collected following centrifugation at $15,000 \mathrm{~g}$ for $15 \mathrm{~min}$. Thawed blackberry fruit was homogenized for 3 min using a Waring blender and then centrifuged (Biofuge Primo, Thermo Scientific, Waltham, MA, USA) twice at $15,000 \mathrm{~g}$ for $15 \mathrm{~min}$ each to generate a clear juice. Supernatants were then stored at $-20^{\circ} \mathrm{C}$ during the period of study. The blackberry and pear supernatants were either used as $100 \%$ pure samples or combined at a ratio of 30:70. The fruit extracts were stored at $4^{\circ} \mathrm{C}$ during fermentation and analysis.

\section{Bacterial Strains and Other Materials}

Strains of LAB used in this study were L. helveticus R0052 that was supplied by Rosell Institute Inc., Montreal, Canada (Lot\# XA 0145, Seq\# 00014160) and Bifidobacterium longum isolated from a previous study (Apostolidis et al., 2007) and H. pylori ATCC 43,579 of human gastric origin that was provided by American Type Culture Collection (Rockville, MD, USA).

\section{Fermentation With Lactobacillus helveticus R0052 and Bifidobacterium longum}

Initially, $100 \mu \mathrm{L}$ of L. helveticus R0052 and of B. longum frozen stock (kept in $-80^{\circ} \mathrm{C}$ freezer with cryo-preservative media containing $25 \%$ glycerol) were inoculated into $10 \mathrm{~mL}$ of MRS broth (Difco) and incubated at $37^{\circ} \mathrm{C}$ for $16 \mathrm{~h}$. A $100 \mu \mathrm{L}$ volume of the overnight grown culture were sub-cultured to $10 \mathrm{~mL}$ of MRS broth and incubated again at $37^{\circ} \mathrm{C}$ for $16 \mathrm{~h}$ under aerobic condition and used as inoculum. An inoculum size of $10 \mathrm{~mL}(\mathrm{v} / \mathrm{v})$ was added aseptically to the $100 \%$ Kiowa blackberry, $100 \%$ Bartlett pear, or the 30:70 blackberry: pear combination to achieve a total volume of $100 \mathrm{~mL}$ in a $125-\mathrm{mL}$ sterile Erlenmeyer flask and incubated at $37^{\circ} \mathrm{C}$ (closed chamber incubator) under static condition. Initial $\mathrm{pH}$ was measured and adjusted to 6 using $1 \mathrm{~N} \mathrm{NaOH}$ at $0 \mathrm{~h}$ fermentation. Fermentation followed at $37^{\circ} \mathrm{C}$ and $13 \mathrm{~mL}$ of samples were taken out at 0,24 and $48 \mathrm{~h}$. At every time point, the inoculated sample was placed into 2 different tubes. Prior to any assays, one tube was adjusted to $\mathrm{pH} 6$ using $1 \mathrm{~N}$ $\mathrm{NaOH}$, while the $\mathrm{pH}$ of another tube was not adjusted (labeled as fermented acidic $\mathrm{pH}$ ) and added with distilled water to keep the volume same. All samples were then centrifuged at 15,000 g for $15 \mathrm{~min}$ and used for the in vitro assays.

\section{Absorbance of Samples and Colony Counts}

Absorbance was measured before the final $\mathrm{pH}$ treatment. Turbidity of the fermented samples at every time point was estimated using absorbance at $600 \mathrm{~nm}$ as an indicator of bacterial growth. More accurate estimation of living cells was made by plate count method and expressed as $\mathrm{CFU} / \mathrm{mL}$. At 0, 24, and $48 \mathrm{~h}, 100 \mu \mathrm{L}$ of the appropriate dilution were plated on MRS Agar and incubated at $37^{\circ} \mathrm{C}$ for $24 \mathrm{~h}$ in anaerobic BBL GasPak jars (Becton, Dickinson \& Co. Saprks, MD, USA) containing BD 
GasPak EZ anaerobe container system sachets with indicator to help maintain the anaerobic environment. Individual colonies were counted in the valid range of 25-250 to determine the $\mathrm{CFU} / \mathrm{mL}$ of each sample.

\section{Total Soluble Phenolics Assay}

Total phenolic content of blackberry, pear, and blackberry: pear combination were determined using a colorimetric assay modified by Shetty et al. (1995). A volume of $500 \mu \mathrm{L}$ of fruit extracts and $500 \mu \mathrm{L}$ of distilled water were transferred into a test tube to which $1 \mathrm{~mL}$ of $95 \%$ ethanol, $5 \mathrm{~mL}$ of distilled water, and $0.5 \mathrm{~mL}$ of $50 \%(\mathrm{v} / \mathrm{v})$ Folin-Ciocalteu reagent, respectively were added. The mixture was left to incubate for $5 \mathrm{~min}$, followed by the addition of $1 \mathrm{~mL}$ of $5 \% \mathrm{Na}_{2} \mathrm{CO}_{3}$. After thorough mixing, the reaction mixture was incubated in the dark for $60 \mathrm{~min}$ and the absorbance was read at $725 \mathrm{~nm}$ in a spectrophotometer (Genesys Thermo Fisher, Waltham, MA, USA). Standard curves were prepared using increasing concentrations of gallic acid in $95 \%$ ethanol. Absorbance values were converted to total soluble phenolics and expressed as mg of gallic acid equivalent (GAE) per $\mathrm{g}$ fresh weight of fruit extracts.

\section{Antioxidant Activity by 2,2-Diphenyl-1-Picrylhydrazyl (DPPH) Radical Inhibition Assay}

Total antioxidant activity of blackberry, pear, and their 30:70 combination were measured using a modified DPPH radical inhibition assay (Sarkar et al., 2016). In a microcentrifuge tube, a volume of $0.25 \mathrm{~mL}$ sample mixture was added to $1.25 \mathrm{~mL}$ of $60 \mu \mathrm{M}$ DPPH in $95 \%$ ethanol. During $5 \mathrm{~min}$ of incubation, the samples were vortexed and then centrifuged at 15,000 $\mathrm{g}$ for $1 \mathrm{~min}$. The absorbance $(A)$ was read at $517 \mathrm{~nm}$. As a control, $0.25 \mathrm{~mL}$ of $95 \%$ ethanol was used instead of a sample mixture. The antioxidant activity was expressed as \% inhibition of DPPH radical formation and calculated using the following formula:

$$
\text { DPPH Inhibition }(\%)=\frac{(\text { Abs control }- \text { Abs sample })}{\text { Abs control }} \times 100
$$

\section{$\alpha$-Glucosidase Enzyme Inhibition Assay}

The anti-hyperglycemic property relevant $\alpha$-glucosidase enzyme inhibition assay was performed following a method described by McCue et al. (2005). Initially, $50 \mu \mathrm{L}$ of sample was added with 100 $\mu \mathrm{L}$ of $0.1 \mathrm{M}$ phosphate buffer containing ( $\mathrm{pH}$ 6.9) $\alpha$-glucosidase enzyme solution $(1.0 \mathrm{U} / \mathrm{mL})$ in 96 -well microplates. Half and one-fifth diluted samples were also used to determine a potential dose dependent response. The mixed solutions were incubated at $25^{\circ} \mathrm{C}$ for $10 \mathrm{~min}$. After incubation, $50 \mu \mathrm{L}$ of $5 \mathrm{mM}$ p-nitrophenyl$\alpha$-D-glucopyranoside solution in $0.1 \mathrm{M}$ phosphate buffer ( $\mathrm{pH}$ 6.9) was added to each well at timed intervals. The reaction mixtures were then incubated at $25^{\circ} \mathrm{C}$ for $5 \mathrm{~min}$. Before and after that $5 \mathrm{~min}$ incubation, absorbances $(A)$ reading were recorded at $405 \mathrm{~nm}$ by a microplate reader (Thermomax, Molecular Device Co., VA, USA) and the difference between 0 - and 5-min readings were noted as $\Delta A$. For the control, $50 \mu \mathrm{L}$ of buffer solution was added instead of the sample. The result was expressed as \% inhibition of $\alpha$-glucosidase and calculated using the following formula:

$$
\begin{aligned}
\alpha-\text { Glucosidase Inhibition }(\%) & =\frac{(\text { Abs control }- \text { Abs sample })}{\text { Abs control }} \\
& \times 100
\end{aligned}
$$

\section{$\alpha$-Amylase Enzyme Inhibition Assay}

In vitro assay model described by McCue et al. (2005) was used to determine $\alpha$-amylase inhibitory activity of fermented and unfermented blackberry-based fruit extracts. Undiluted, onefifth and one-tenth diluted samples were tested to obtain a dose depended response. For the assay, a total volume of 500 $\mu \mathrm{L}$ of sample comprised of $500 \mu \mathrm{L}$ for undiluted, $100 \mu \mathrm{L}$ of sample and $400 \mu \mathrm{L}$ of distilled water (1/5 concentration) or $50 \mu \mathrm{L}$ of sample combined with $450 \mu \mathrm{L}$ of distilled water (1/10 concentration) were used. The water and sample mixtures with $500 \mu \mathrm{L}$ of $0.02 \mathrm{M}$ sodium phosphate buffer $(\mathrm{pH} 6.9$ with $0.006 \mathrm{M}$ sodium chloride) containing $\alpha$-amylase enzyme solution $(0.5 \mathrm{mg} / \mathrm{mL})$ were combined and were incubated at $25^{\circ} \mathrm{C}$ for $10 \mathrm{~min}$. After incubation, $500 \mu \mathrm{L}$ of $1 \%(\mathrm{w} / \mathrm{v})$ starch solution that were prepared in $0.02 \mathrm{M}$ sodium phosphate buffer ( $\mathrm{pH} 6.9$ with $0.006 \mathrm{M}$ sodium chloride) was added to each tube at timed intervals and then incubated for additional $10 \mathrm{~min}$. The reaction was stopped with the addition of $1.0 \mathrm{~mL}$ of dinitrosalicylic acid color reagent. The test tubes were then incubated in a boiling water bath for $10 \mathrm{~min}$ and cooled down to the room temperature. The reaction mixture was then diluted with $10 \mathrm{~mL}$ of distilled water and the absorbance $(A)$ was read at $540 \mathrm{~nm}$. The result was expressed as \% inhibition of $\alpha$-amylase and calculated using the following formula:

$$
\begin{aligned}
& \alpha-\text { Amylase Inhibition }(\%) \\
& =\left(\frac{\text { Abs control }-(\text { Abs sample }- \text { Abs Sample Blank })}{\text { Abs Control }} \times 100\right.
\end{aligned}
$$

\section{Angiotensin-1- Converting Enzyme Inhibition Assay}

The ACE inhibitory activity was measured using a modified assay described by McCue et al. (2005). A volume of $50 \mu \mathrm{L}$ of sample was incubated with $200 \mu \mathrm{L}$ of $0.1 \mathrm{M} \mathrm{NaCl}$-borate buffer ( $\mathrm{pH} 8.3$ ) containing $2.0 \mathrm{mU}$ ACE-I solution at $25^{\circ} \mathrm{C}$ for $10 \mathrm{~min}$. After incubation, $100 \mu \mathrm{L}$ of $5 \mathrm{mM}$ substrate solution (hippurylhistidine-leucine, HHL) was added. The reaction mixture was incubated at $37^{\circ} \mathrm{C}$ for an hour. The reaction was then stopped with the addition of $150 \mu \mathrm{L}$ of $0.5 \mathrm{~N} \mathrm{HCl}$. The product of ACE reaction, hippuric acid, was detected and quantified using high performance liquid chromatography (HPLC) method.

Five microliters of sample were injected using Agilent ALS 1100 autosampler into an Agilent 1100 series HPLC (Agilent Technologies, Palo Alto, CA) equipped with DAD 1100 diode array detector. The solvents used for gradient elution were (A) $10 \mathrm{mM}$ phosphoric acid ( $\mathrm{pH} 2.5)$ and (B) 100\% methanol. The methanol concentration was increased to $60 \%$ for the first $8 \mathrm{~min}$, and to $100 \%$ for the next $5 \mathrm{~min}$, then decreased to $0 \%$ for the last $5 \mathrm{~min}$ (total run time is $18 \mathrm{~min}$ ). Nucleosil 100-5C18, 250 $\times 4.6 \mathrm{~mm}$ i.d., was the analytical column used with packing 
material of $5 \mu \mathrm{m}$ particle size at a flow rate $1 \mathrm{~mL} / \mathrm{min}$ at ambient temperature. During each run, the chromatogram was recorded at $228 \mathrm{~nm}$ and integrated using Agilent Chemstation enhanced integrator for detection of liberated hippuric acid. The peak area of hippuric acid $(E)$ chromatogram was noted. Pure hippuric acid was used to calibrate the standard curve and retention time. The result was expressed as \% inhibition of ACE and calculated using the following formula:

$$
\begin{aligned}
\text { ACE Inhibition }(\%) & =\frac{((\text { Abs control }- \text { Abs blank })-\text { Abs sample })}{(\text { Abs control }- \text { Abs blank })} \\
& \times 100
\end{aligned}
$$

\section{HPLC Analysis of Phenolic Profiles}

Two milliliters of blackberry, pear or the 30:70 combination was filtered through a $0.2 \mu \mathrm{m}$ filter. A volume of $5 \mu \mathrm{L}$ sample was injected using Agilent ALS 1100 autosampler into an Agilent 1100 series HPLC (Agilent Technologies, Palo Alto, CA, USA) equipped with DAD 1100 diode array detector. The solvents used for gradient elution were (A) $10 \mathrm{mM}$ phosphoric acid (pH 2.5) and (B) 100\% methanol. The methanol concentration was increased to $60 \%$ for the first $8 \mathrm{~min}$ and to $100 \%$ over the next $7 \mathrm{~min}$, then decreased to $0 \%$ for the next $3 \mathrm{~min}$ and was maintained for the next $7 \mathrm{~min}$ (total run time is $25 \mathrm{~min}$ ). The analytical column used was Agilent Zorbax SB-C18, 250 $\times 4.6 \mathrm{~mm}$ i.d., with packing material of $5 \mu \mathrm{m}$ particle size at a flow rate of $1 \mathrm{~mL} / \mathrm{min}$ at ambient temperature. During each run, the chromatogram was recorded at 225 and $306 \mathrm{~nm}$ and integrated using Agilent Chemstation enhanced integrator. Pure standards of gallic acid, protocatechuic acid, chlorogenic acid, caffeic acid, resveratrol, rutin, p-coumaric acid, m-coumaric acid, and rosmarinic acid in $100 \%$ methanol were used to calibrate the standard curves and retention times.

\section{Preparation of $\boldsymbol{H}$. pylori Culture}

H. pylori was grown according to Stevenson et al. (2000). Standard plating medium was composed of $10 \mathrm{~g}$ of special peptone (Oxoid Ltd, Basing-Stoke, England), $15 \mathrm{~g}$ of granulated agar (Difco Laboratories, Becton, Dickinson and Co., Sparks, $\mathrm{MD}, \mathrm{USA}$ ), $5 \mathrm{~g}$ of sodium chloride (EM Science, Gibbstown, NJ, USA), $5 \mathrm{~g}$ of yeast extract (Difco) and $5 \mathrm{~g}$ of beef extract (Difco) per liter of water. Broth media were consisted of $10 \mathrm{~g}$ of special peptone (Oxoid Ltd) per liter, $5 \mathrm{~g}$ of sodium chloride (EM Science) per liter, $5 \mathrm{~g}$ of yeast extract (Difco) per liter, and $5 \mathrm{~g}$ of beef extract (Difco) per liter of water. One milliliter of $H$. pylori stock culture was inoculated to $10 \mathrm{~mL}$ of sterile broth medium and incubated at $37^{\circ} \mathrm{C}$ for $24 \mathrm{~h}$. To make bacterial lawn for the agar-diffusion assay active culture was then spread on $H$. pylori standard plating agar plates.

\section{Agar-Diffusion Assay}

The antimicrobial activity of the fermented sample extracts on $H$. pylori was analyzed by agar-diffusion method. Sterile $12.7 \mathrm{~mm}$ diameter paper disks (Schleicher \& Schuell, Inc., Keene, NH) were placed on the surface of seeded agar plates. The test extracts were sterilized using $0.22 \mu \mathrm{m}$ Milipore filter membrane (Fisher Scientific, Pittsburgh, PA, USA). One hundred microliters of test extracts were aseptically added onto the paper disks. Distilled water was used as control. Treated plates were incubated at $37^{\circ} \mathrm{C}$ for $48 \mathrm{~h}$ in BBL GasPak jars (Becton, Dickinson and Co., Sparks, $\mathrm{MD}$, USA) with BD GasPak Campy container system sachets (Becton, Dickinson and Co., Sparks, MD, USA). Each experiment was repeated twice and consisted of triplicates (3 disks per sample or treatment in 1 plate). Diameter (D) of clear zone surrounding each disk was measured (in millimeter).

\section{Proline Growth Response Assay}

The inhibition mechanism of $H$. pylori mediated by phenolic phytochemicals was proposed by Shetty and Wahlqvist (2004). Bacterial lawns of $H$. pylori were prepared as described previously. The standard plating medium was modified by the addition of Proline to a final concentration of $5 \mathrm{mM}$. A similar protocol as mentioned in the agar-diffusion assay was followed.

\section{Statistical Analysis}

All experiments were performed in triplicate and repeated three times each. Means and standard errors from all three experimental runs were calculated and combined data analysis was performed using Microsoft Excel XP. Statistically significant differences between fruit sample, fermentation treatments, fermentation time points, and their respective interactions were determined using repeated measurement ANOVA model and using multivariate data arrangement. The least significant difference at $p<0.05$ confidence level between fruit sample extracts $\times$ fermentation treatments interactions for each parameters was calculated separately for each fermentation time point using Tukey's test.

\section{RESULTS AND DISCUSSION \\ Total Soluble Phenolic Content and Phenolic Profile}

Folin-Ciocalteu based colorimetric assay method was used to determine total soluble phenolic content of unfermented and LAB-fermented fruit synergy and pure extracts of blackberry and pear. Statistically significant differences $(p \leq 0.05)$ in total soluble phenolic content between fruit samples, fermentation treatments, fruit sample $\times$ fermentation treatment interactions within fermentation time points were observed (Figure 1). Additionally, statistically significant $(p \leq 0.05)$ differences in phenolic content between fermentation time points were also observed. As expected, high total soluble phenolic content was observed in Kiowa blackberry extracts (100\%) when compared with pure Bartlett pear (100\%) and blackberry: pear (30:70) combination across all fermentation time points (Figure 1). The total soluble phenolic content of Kiowa blackberry and Bartlett pear extracts found in this study corroborated with our previous findings (Sarkar et al., 2015, 2016). Significant improvement over baseline and proportional (v:v) phenolic content of individual pear and blackberry was also found in 30:70 blackberry: pear combination following fermentation with B. longum. Previously, Agustinah et al. (2016) reported increase in total soluble phenolic content with proportional increase of blueberry juice in apple: blueberry 


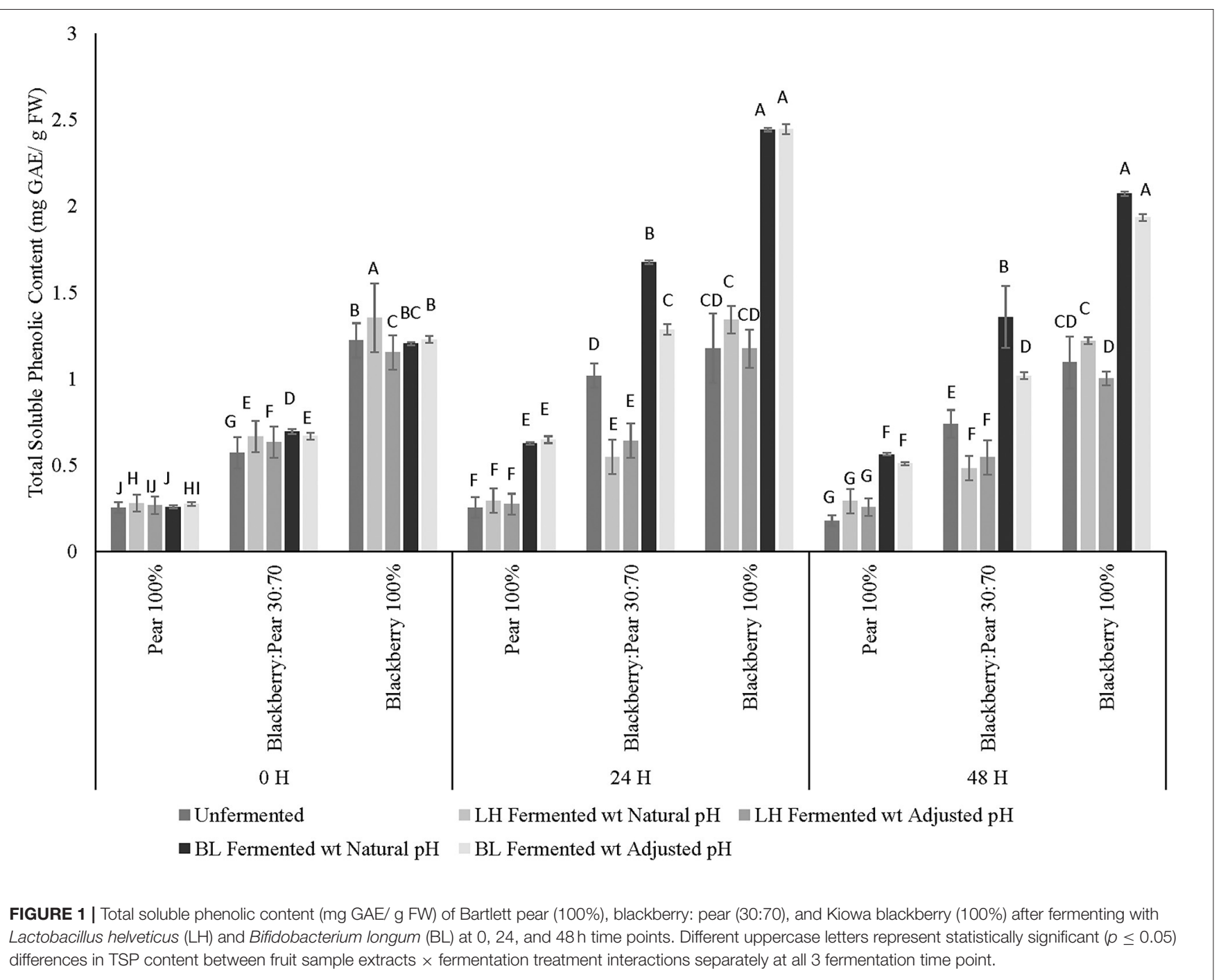

fruit synergy. In another study, Gunathilake et al. (2013) found high phenolic content in apple: cranberry: blueberry (equal proportion) combination, which were targeted for functional beverage design.

At $0 \mathrm{~h}$ time point $L$. helveticus fermented samples with natural acidic $\mathrm{pH}$ had significantly high soluble phenolic content followed by B. longum fermented fruit combinations. Additionally, at 24 and $48 \mathrm{~h}$ fermentation time points, fermentation with $B$. longum resulted in higher total soluble phenolic content, which was statistically significant $(p \leq 0.05)$ irrespective of fruit substrates and fermentation time points. Higher stability and retention of soluble phenolics was observed in all three substrates (100\% pure extracts of blackberry and pear and their combination at 30:70 ratio) and after $48 \mathrm{~h}$ fermentation with $B$. longum. In a previous study, improvement in total phenolic content was observed following fermentation of Myrtle berry with Lactobacillus plantarum (Curiel et al., 2015). Similarly, Kaprasob et al. (2017) found improvement in phenolic bioactive content in cashew apple extracts after 12 and $24 \mathrm{~h}$ fermentation with select LAB strains. Ankolekar et al. (2011) reported higher retention of phenolic bioactives in cherry extracts under natural acidic $\mathrm{pH}$ condition after $72 \mathrm{~h}$ fermentation with $L$. helveticus (previously reported as Lactobacillus acidophilus). In the current study, no statistically significant differences in total soluble phenolic content were observed between $\mathrm{pH}$ adjusted and unadjusted sample of LAB fermented fruit extracts. Results of this current study indicated that improvement of total phenolic content in B. longum fermented fruit substrates was not just due to the changes in $\mathrm{pH}$, but fermentation might also have beneficial impact on solubilization and mobilization of phenolic bioactives present in the respective fruit matrix and in their combination (30:70).

Therefore, to improve retention of soluble phenolics and subsequent bioactive enrichment in blackberry-based foods and beverages, it is important to advance both compatible fruit synergy and beneficial LAB-based (B. longum) fermentation. In addition to total soluble phenolic content, understanding phenolic compound composition and their changes following 
TABLE 1 | Profile and concentration of phenolic compounds ( $\mu \mathrm{g} / \mathrm{g}$ FW) in Bartlett pear (100\%), 30:70 (blackberry: pear) combination, and Kiowa blackberry (100\%) extracts following fermentation with Lactobacillus helveticus (LH) and Bifidobacterium longum (BL) at $0 \mathrm{~h} \mathrm{(A),} 24 \mathrm{~h} \mathrm{(B),} \mathrm{and} 48 \mathrm{~h}$ (C) time points.

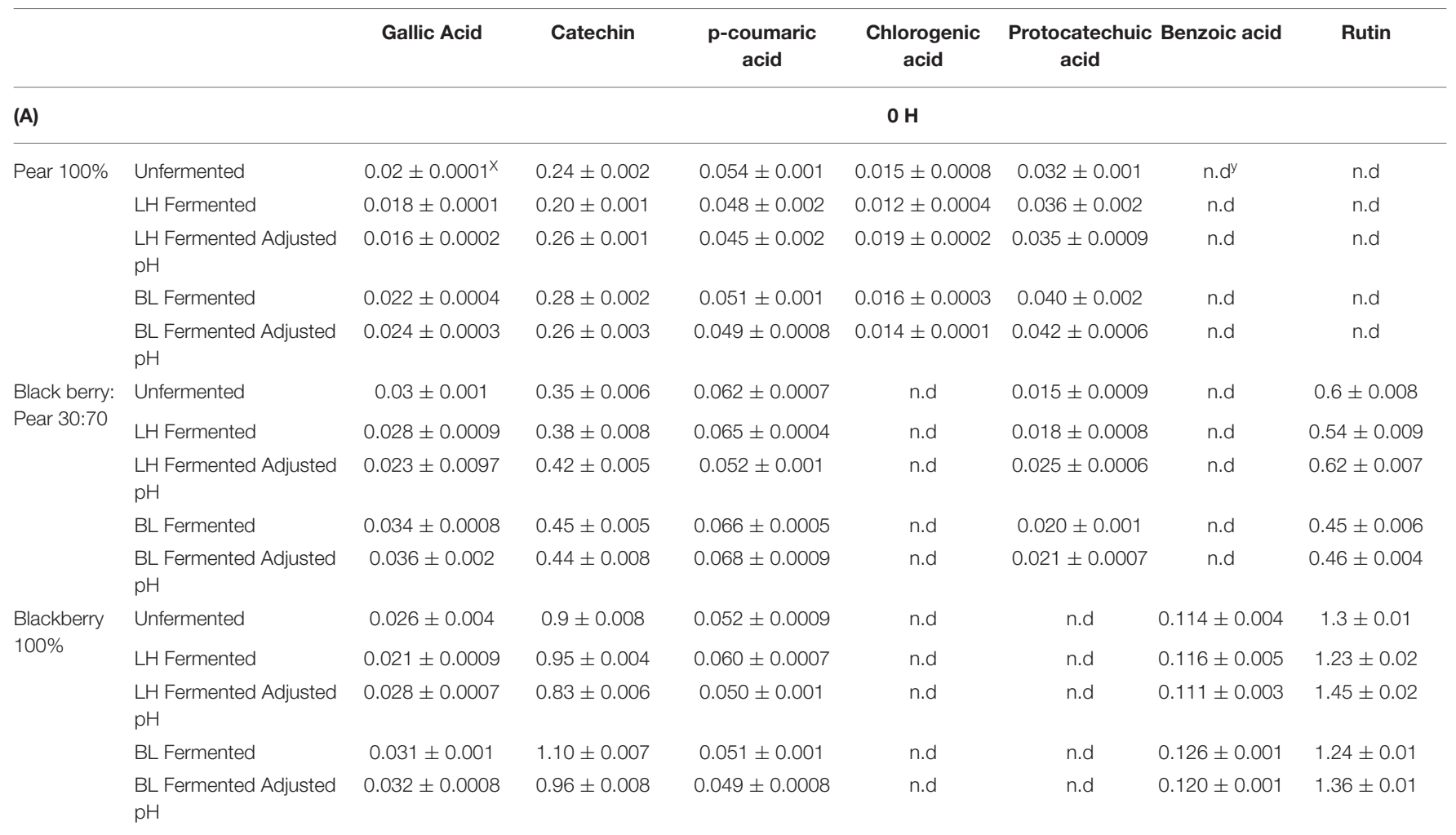

(B)

\begin{aligned} \hline Pear 100\% & Unfermented \\ & LH Fermented \\ & LH Fermented Adjusted \\ & $\mathrm{pH} \\ &$ BL Fermented \\ & BL Fermented Adjusted \\ & pH \end{aligned}

Black berry: Unfermented

Pear 30:70 LH Fermented

LH Fermented Adjusted $\mathrm{pH}$

BL Fermented

BL Fermented Adjusted $\mathrm{pH}$

Blackberry Unfermented $100 \%$

$0.017 \pm 0.0003$

$0.017 \pm 0.0003$

$0.02 \pm 0.0006$

$0.014 \pm 0.0001$

$0.024 \pm 0.0001$

$0.022 \pm 0.0002$

$0.032 \pm 0.0009$

$0.036 \pm 0.001$

$0.028 \pm 0.001$

$0.038 \pm 0.0007$

$0.035 \pm 0.0009$

$0.024 \pm 0.0001$

$0.026 \pm 0.0006$

$0.030 \pm 0.0006$

LH Fermented Adjusted

$\mathrm{pH}$

BL Fermented

$0.033 \pm 0.0014$

BL Fermented Adjusted $\mathrm{pH}$

$0.030 \pm 0.001$
$24 \mathrm{H}$

$\begin{array}{lccccc}0.20 \pm 0.001 & 0.042 \pm 0.0008 & 0.011 \pm 0.0001 & 0.030 \pm 0.001 & \text { n.d } & \text { n.d } \\ 0.23 \pm 0.002 & 0.040 \pm 0.001 & 0.013 \pm 0.0006 & 0.030 \pm 0.002 & \text { n.d } & \text { n.d } \\ 0.24 \pm 0.001 & 0.047 \pm 0.0006 & 0.014 \pm 0.0004 & 0.031 \pm 0.001 & \text { n.d } & \text { n.d } \\ & & & & & \\ 0.25 \pm 0.001 & 0.044 \pm 0.0009 & 0.011 \pm 0.0001 & 0.042 \pm 0.002 & \text { n.d } & \text { n.d } \\ 0.22 \pm 0.001 & 0.046 \pm 0.001 & 0.016 \pm 0.0001 & 0.044 \pm 0.0009 & \text { n.d } & \text { n.d } \\ & & & & & \\ 0.31 \pm 0.006 & 0.058 \pm 0.0006 & \text { n.d } & 0.010 \pm 0.0003 & \text { n.d } & 0.3 \pm 0.006 \\ 0.28 \pm 0.001 & 0.061 \pm 0.002 & \text { n.d } & 0.011 \pm 0.0002 & \text { n.d } & 0.23 \pm 0.005 \\ 0.36 \pm 0.004 & 0.050 \pm 0.001 & \text { n.d } & 0.015 \pm 0.0001 & \text { n.d } & 0.36 \pm 0.002 \\ & & & & & \\ 0.33 \pm 0.002 & 0.059 \pm 0.001 & \text { n.d } & 0.018 \pm 0.0009 & \text { n.d } & 0.32 \pm 0.001 \\ 0.34 \pm 0.001 & 0.054 \pm 0.001 & \text { n.d } & 0.016 \pm 0.0005 & \text { n.d } & 0.40 \pm 0.001 \\ 0.84 \pm 0.008 & 0.045 \pm 0.001 & \text { n.d } & \text { n.d } & 0.108 \pm 0.001 & 1.2 \pm 0.008 \\ 0.98 \pm 0.002 & 0.050 \pm 0.0009 & \text { n.d } & \text { n.d } & 0.104 \pm 0.001 & 1.31 \pm 0.009 \\ 0.95 \pm 0.001 & 0.055 \pm 0.0008 & \text { n.d } & \text { n.d } & 0.113 \pm 0.005 & 1.36 \pm 0.009 \\ 0.96 \pm 0.008 & 0.052 \pm 0.0006 & \text { n.d } & \text { n.d } & 0.120 \pm 0.002 & 1.34 \pm 0.01 \\ 0.90 \pm 0.006 & 0.056 \pm 0.0007 & \text { n.d } & \text { n.d } & 0.124 \pm 0.002 & 1.40 \pm 0.008\end{array}$

$0.90 \pm 0.006$
(C)

Pear 100\% Unfermented

LH Fermented

$48 \mathrm{H}$

$\begin{array}{ccccccc}0.012 \pm 0.0001 & 0.15 \pm 0.001 & 0.032 \pm 0.001 & 0.009 \pm 0.0007 & 0.024 \pm 0.0009 & \text { n.d } & \text { n.d } \\ 0.016 \pm 0.0001 & 0.21 \pm 0.001 & 0.042 \pm 0.0007 & 0.016 \pm 0.0001 & 0.022 \pm 0.0006 & \text { n.d } & \text { n.d }\end{array}$

(Continued) 


\begin{tabular}{|c|c|c|c|c|c|c|c|c|}
\hline & & Gallic Acid & Catechin & $\begin{array}{l}\text { p-coumaric } \\
\text { acid }\end{array}$ & $\begin{array}{l}\text { Chlorogenic } \\
\text { acid }\end{array}$ & $\begin{array}{l}\text { Protocatechuic } \\
\text { acid }\end{array}$ & Benzoic acid & Rutin \\
\hline & $\begin{array}{l}\text { LH Fermented Adjusted } \\
\mathrm{pH}\end{array}$ & $0.014 \pm 0.0001$ & $0.20 \pm 0.002$ & $0.043 \pm 0.001$ & $0.013 \pm 0.0001$ & $0.023 \pm 0.0007$ & n.d & n.d \\
\hline & BL Fermented & $0.020 \pm 0.0006$ & $0.24 \pm 0.002$ & $0.050 \pm 0.001$ & $0.012 \pm 0.0002$ & $0.034 \pm 0.0009$ & n.d & n.d \\
\hline & $\begin{array}{l}\text { BL Fermented Adjusted } \\
\mathrm{pH}\end{array}$ & $0.019 \pm 0.0001$ & $0.23 \pm 0.003$ & $0.043 \pm 0.0006$ & $0.015 \pm 0.0002$ & $0.034 \pm 0.001$ & n.d & n.d \\
\hline \multirow{4}{*}{$\begin{array}{l}\text { Black berry: } \\
\text { Pear 30:70 }\end{array}$} & LH Fermented & $0.033 \pm 0.002$ & $0.32 \pm 0.001$ & $0.054 \pm 0.0008$ & n.d & $0.010 \pm 0.0001$ & n.d & $0.2 \pm 0.005$ \\
\hline & $\begin{array}{l}\text { LH Fermented Adjusted } \\
\mathrm{pH}\end{array}$ & $0.029 \pm 0.001$ & $0.31 \pm 0.002$ & $0.053 \pm 0.0009$ & n.d & $0.016 \pm 0.0001$ & n.d & $0.18 \pm 0.002$ \\
\hline & BL Fermented & $0.036 \pm 0.001$ & $0.35 \pm 0.003$ & $0.060 \pm 0.001$ & n.d & $0.012 \pm 0.0003$ & n.d & $0.34 \pm 0.001$ \\
\hline & $\begin{array}{l}\text { BL Fermented Adjusted } \\
\mathrm{pH}\end{array}$ & $0.033 \pm 0.0007$ & $0.32 \pm 0.001$ & $0.064 \pm 0.0007$ & n.d & $0.014 \pm 0.0004$ & n.d & $0.33 \pm 0.001$ \\
\hline \multirow{3}{*}{$\begin{array}{l}\text { Blackberry } \\
100 \%\end{array}$} & $\begin{array}{l}\text { LH Fermented Adjusted } \\
\mathrm{pH}\end{array}$ & $0.030 \pm 0.0006$ & $0.90 \pm 0.004$ & $0.051 \pm 0.0009$ & n.d & n.d & $0.115 \pm 0.005$ & $1.2 \pm 0.008$ \\
\hline & BL Fermented & $0.033 \pm 0.0014$ & $0.84 \pm 0.002$ & $0.046 \pm 0.0009$ & n.d & n.d & $0.114 \pm 0.004$ & $1.23 \pm 0.009$ \\
\hline & $\begin{array}{l}\text { BL Fermented Adjusted } \\
\mathrm{pH}\end{array}$ & $0.030 \pm 0.001$ & $0.94 \pm 0.001$ & $0.051 \pm 0.0005$ & n.d & n.d & $0.120 \pm 0.003$ & $1.28 \pm 0.009$ \\
\hline
\end{tabular}

$x_{ \pm}$Standard Error.

$y_{\text {n.d-not detected. }}$

fruit synergy and LAB-based fermentation is also essential to develop wider fruit based functional foods and beverages.

The major phenolic compounds found in 30:70 blackberry: pear combination were gallic acid, catechin, p-coumaric acid, protocatechuic acid, and rutin (Table 1). Cholorgenic acid was observed only in $100 \%$ Bartlett pear extract, while $100 \%$ Kiowa blackberry extracts had benzoic acid. Protocatechuic acid was not found in $100 \%$ Kiowa blackberry, but 30:70 blackberry: pear combination had protocatechuic acid due to the integration of pear in this fruit synergy. Similarly, addition of blackberry resulted into significant rutin content in 30:70 blackberry: pear fruit combination. The result of this study indicated that integration of compatible fruit synergy can potentially widen phenolic bioactive profile and their associated functionalities in fruit combination derived foods and beverages. In previous optimization study, similar profile of phenolic compounds was found in blackberry: pear combination (Warner, 2012). Additionally, these are also the most common phenolic compounds reported in pear and blackberry extracts by previous studies (Sarkar et al., 2015, 2016; Willems and Low, 2018; Schulz et al., 2019; Liao et al., 2020).

Like the results of total soluble phenolic content, significant changes in individual phenolic compounds following LAB fermentation of fruit substrates was also observed (Table 1). Specifically, catechin, p-coumaric acid, and rutin content of $100 \%$ blackberry, 100\% pear, and 30:70 blackberry: pear combination increased with LAB fermentation. Overall, higher retention and stability of phenolic compounds were observed after $48 \mathrm{~h}$ with $\mathrm{LAB}$ fermentation. Catechin and rutin can be found in bound forms in fruits and $\mathrm{LAB}$ fermentation potentially released these compounds in food and beverage matrices (Su et al., 2014).
Benzoic acid content of $100 \%$ blackberry extracts also increased with LAB fermentation and maintained at higher level even after 48 h. Previously, Park et al. (2017) found increases in benzoic acid and benzaldehyde after fermenting mixed berry juice with L. plantarum. Similarly, Ryu et al. (2019) reported increased protocatechuic acid and catechol in LAB fermented blueberry. The results of the current and other reported studies indicated that LAB-based bioprocessing is an effective strategy to improve stability of phenolic compounds in berry and other fruit extracts. Such improvement in phenolic bioactive retention following LAB-based fermentation is relevant for enhancing human health protective qualities as well as improving postharvest preservation qualities of pear, blackberry and foods and beverages derived from these fruits. As phenolic compounds of blackberry and pear have antioxidant benefits, improvement in their retention and stability potentially leads into enhanced antioxidant activity in bioprocessed substrates.

\section{Antioxidant Functionality}

Total antioxidant activity of fermented and unfermented extracts of pure blackberry, pear, and blackberry: pear (30:70) combination was determined using DPPH-free radical scavenging assay. Overall, moderate to high antioxidant activity (41-82\% inhibition) was observed across all fermentation time points and three different fruit substrates (Figure 2). Similar to the results of total soluble phenolic content, antioxidant activity of fruit extracts varied significantly $(p \leq 0.05)$ between 3 fruit samples, fermentation treatments, fermentation time points, and fruit sample $\times$ fermentation treatment interactions. Blackberry: pear (30:70) combination had significantly $(p \leq 0.05)$ higher DPPH-based antioxidant activity after $48 \mathrm{~h}$ fermentation 


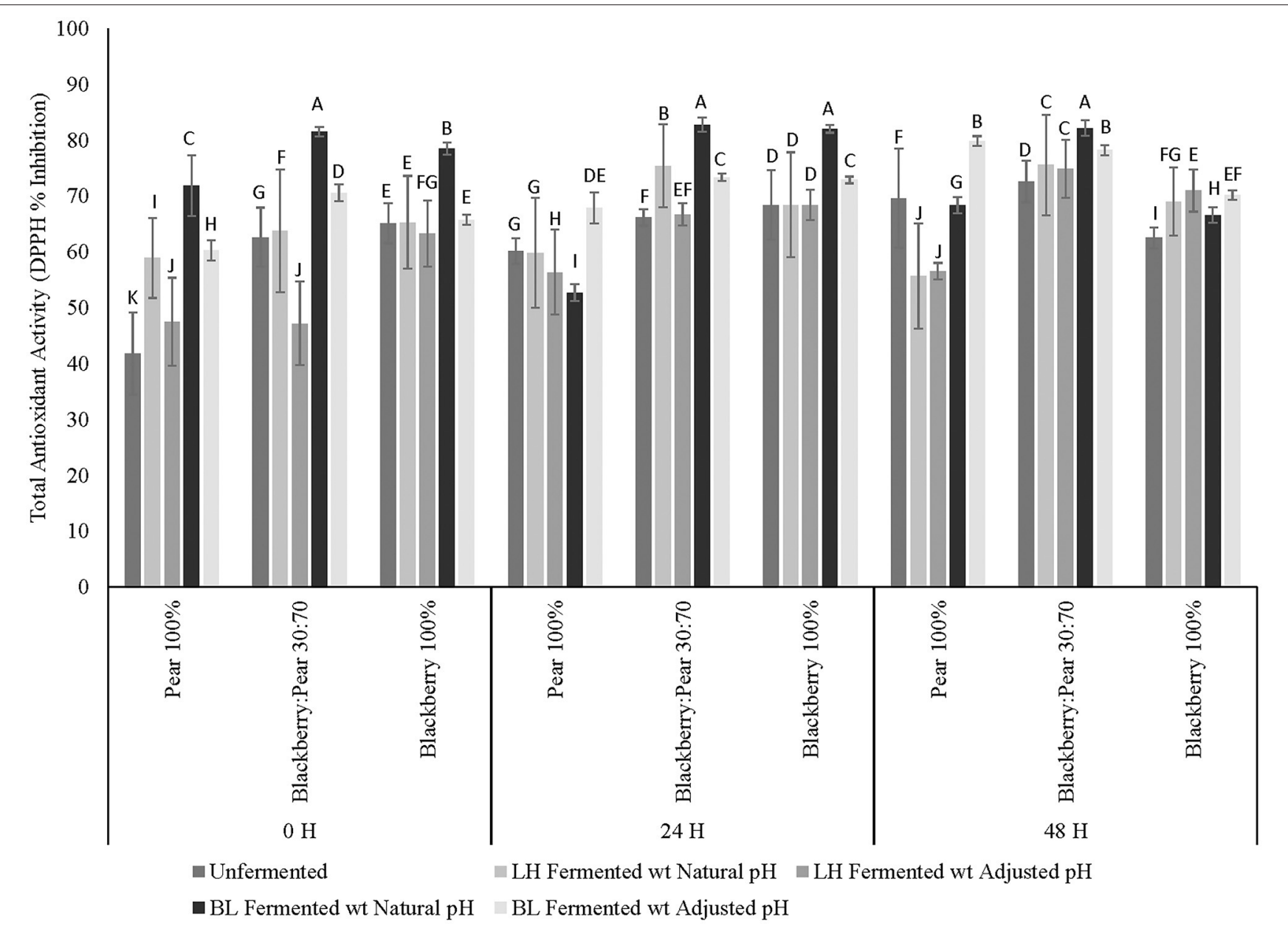

FIGURE 2 | Total antioxidant activity (DPPH-based inhibition) of Bartlett pear (100\%), blackberry: pear (30:70), and Kiowa blackberry (100\%) after fermenting with Lactobacillus helveticus ( $\mathrm{LH}$ ) and Bifidobacterium longum (BL) at 0,24 , and $48 \mathrm{~h}$ time points. Different uppercase letters represent statistically significant $(p \leq 0.05)$ differences in antioxidant activity between fruit sample extracts $\times$ fermentation treatment interactions separately at all 3 fermentation time point.

and incubation (for unfermented sample). Between blackberry and pear, blackberry extracts had higher baseline antioxidant activity. However, with LAB fermentation antioxidant activity of Bartlett pear extracts (100\%) further improved after $48 \mathrm{~h}$ of LAB fermentation.

Like the result of total soluble phenolic content, B. longum fermented sample (natural $\mathrm{pH}$ at 0 and $24 \mathrm{~h}$ and in adjusted $\mathrm{pH}$ at $48 \mathrm{~h}$ ) had significantly $(p \leq 0.05)$ higher antioxidant activity when compared with unfermented and L. helveticus fermented fruit substrates. At 0 , and $24 \mathrm{~h}$ fermentation time points, B. longum fermented sample with natural acidic $\mathrm{pH}$ had higher antioxidant activity when compared with sample of neutral (adjusted) $\mathrm{pH}$. Previously, improved antioxidant activity was observed in several fruit substrates following LAB-based and gut microbiota fermentation (Curiel et al., 2015; Fujita et al., 2017; Kaprasob et al., 2017, 2019; Park et al., 2017; Gowd et al., 2019). In addition to the release of antioxidant bioactives in fermented matrix, some LAB strains can also exhibit strong antioxidant activity (Liu and Pan, 2010). Therefore, redox protective functions of $\mathrm{LAB}$ is extremely relevant to counter oxidative degradation and associated spoilage of plant and dairy based foods and beverages. In addition to improving keeping quality, when recruited for bioprocessing in antioxidant rich fruit substrates, LAB fermentation can further enhance the antioxidant functionalities of fermented foods and beverages. Results of the current study revealed that compatible fruit synergy combining with LABbased fermentation is an effective bioprocessing strategy to improve antioxidant activity of blackberry and pear-derived foods and beverages. The antioxidant enriched blackberry: pear combination following LAB fermentation are relevant for targeting diets to counter chronic oxidative stress-linked diseases such as type 2 diabetes and cardiovascular diseases. However, it is also important to determine other type 2 diabetes relevant functionalities of antioxidant-enriched foods and beverages to integrate them in dietary interventions and support strategies for wider public health solutions with further in vivo studies.

\section{Anti-hyperglycemic Functionality}

Chronic hyperglycemia due to breakdown of glucose homeostasis contributes to pathogenesis of type 2 diabetes. Therefore, 
TABLE 2 | Anti-hyperglycemic property relevant $\alpha$-glucosidase enzyme inhibitory activity of (1/5th, 1/2 and undiluted) Bartlett pear (100\%), 30:70 (blackberry: pear) combination, and Kiowa blackberry (100\%) extracts during (0, 24, and 48 h) fermentation with Lactobacillus helveticus (LH) and Bifidobacterium longum (BL).

\begin{tabular}{|c|c|c|c|c|c|c|c|c|c|c|}
\hline & & \multicolumn{3}{|c|}{$\mathrm{OH}$} & \multicolumn{3}{|c|}{$24 \mathrm{H}$} & \multicolumn{3}{|c|}{$48 \mathrm{H}$} \\
\hline & & 1/5 Dil & 1/2 Dil & Undil & 1/5 Dil & 1/2 Dil & Undil & 1/5 Dil & 1/2 Dil & Undil \\
\hline \multirow[t]{5}{*}{ Pear $100 \%$} & Unfermented & $56 \pm 1.8^{\mathrm{x}} \mathrm{A}^{\mathrm{y}}$ & $70 \pm 4.5 \mathrm{~A}$ & $80 \pm 4.3 \mathrm{~A}$ & $46 \pm 2.3 \mathrm{BC}$ & $52 \pm 3.1 C D$ & $70 \pm 2.0 \mathrm{C}$ & $15 \pm 1.3 \mathrm{~F}$ & $31 \pm 1.8 \mathrm{G}$ & $52 \pm 0.9 F$ \\
\hline & LH Fermented & $50 \pm 2.1 \mathrm{~B}$ & $57 \pm 3.4 \mathrm{~B}$ & $60 \pm 12.6 D$ & $43 \pm 2.4 C$ & $51 \pm 4.2 \mathrm{CD}$ & $62 \pm 1.6 \mathrm{D}$ & $5 \pm 1.2 \mathrm{GH}$ & $11 \pm 1.8 \mathrm{H}$ & $28 \pm 0.6 \mathrm{H}$ \\
\hline & LH Fermented Adj pH & $42 \pm 0.9 \mathrm{C}$ & $50 \pm 2.7 C$ & $68 \pm 3.4 \mathrm{BC}$ & $42 \pm 2.8 C$ & $55 \pm 0.6 \mathrm{AB}$ & $74 \pm 1.3 \mathrm{BC}$ & $2 \pm 1.6 \mathrm{H}$ & $13 \pm 1.8 \mathrm{H}$ & $35 \pm 1.2 \mathrm{G}$ \\
\hline & BL Fermented & $48 \pm 2.4 \mathrm{~B}$ & $51 \pm 1.9 \mathrm{C}$ & $61 \pm 2.7 \mathrm{D}$ & $45 \pm 4.1 \mathrm{BC}$ & $52 \pm 2.5 C D$ & $63 \pm 0.8 \mathrm{D}$ & $7 \pm 2.8 \mathrm{G}$ & $11 \pm 1.8 \mathrm{H}$ & $27 \pm 1.6 \mathrm{H}$ \\
\hline & BL Fermented Adj pH & $49 \pm 3.6 B$ & $52 \pm 2.1 C$ & $60 \pm 1.9 \mathrm{D}$ & $43 \pm 3.8 C$ & $58 \pm 1.4 \mathrm{~A}$ & $75 \pm 1.4 \mathrm{~B}$ & $16 \pm 1.4 \mathrm{~F}$ & $40 \pm 1.8 \mathrm{~F}$ & $63 \pm 1.3 \mathrm{DE}$ \\
\hline \multirow{5}{*}{$\begin{array}{l}\text { Black } \\
\text { berry:Pear } \\
30: 70\end{array}$} & Unfermented & $41 \pm 1.1 \mathrm{C}$ & $54 \pm 1.2 \mathrm{BC}$ & $62 \pm 2.3 \mathrm{D}$ & $44 \pm 1.5 B C$ & $50 \pm 1.4 \mathrm{D}$ & $70 \pm 2.7 C$ & $38 \pm 0.6 C D$ & $41 \pm 1.1 \mathrm{EF}$ & $66 \pm 0.9 C$ \\
\hline & LH Fermented & $36 \pm 2 \mathrm{DE}$ & $52 \pm 0.6 C$ & $60 \pm 2.1 \mathrm{D}$ & $21 \pm 0.7 \mathrm{~F}$ & $43 \pm 1.1 E$ & $51 \pm 1.3 \mathrm{~F}$ & $48 \pm 1.3 \mathrm{~A}$ & $59 \pm 1.2 B$ & $65 \pm 1.1 \mathrm{CD}$ \\
\hline & LH Fermented Adj pH & $32 \pm 1.3 \mathrm{E}$ & $40 \pm 1.7 \mathrm{DE}$ & $66 \pm 1.3 \mathrm{C}$ & $43 \pm 0.6 C$ & $54 \pm 1.6 \mathrm{BC}$ & $76 \pm 2.5 B$ & $38 \pm 1.8 \mathrm{CD}$ & $47 \pm 1.4 \mathrm{D}$ & $68 \pm 1.5 \mathrm{C}$ \\
\hline & BL Fermented & $36 \pm 1.3 \mathrm{DE}$ & $51 \pm 1.1 C$ & $60 \pm 0.9 D$ & $27 \pm 0.9 \mathrm{E}$ & $43 \pm 1.5$ & $55 \pm 1.9 \mathrm{E}$ & $47 \pm 1.2 \mathrm{AB}$ & $58 \pm 1.6 B$ & $63 \pm 1.5 \mathrm{DE}$ \\
\hline & BL Fermented Adj pH & $38 \pm 1.1 \mathrm{D}$ & $54 \pm 0.9 B C$ & $70 \pm 3.2 B$ & $38 \pm 1.2 \mathrm{D}$ & $50 \pm 2.2 \mathrm{D}$ & $63 \pm 1.4 \mathrm{D}$ & $36 \pm 2.5 \mathrm{D}$ & $45 \pm 1.9 \mathrm{DE}$ & $61 \pm 1.8 \mathrm{E}$ \\
\hline \multirow{5}{*}{$\begin{array}{l}\text { Blackberry } \\
100 \%\end{array}$} & Unfermented & $25 \pm 1.1 \mathrm{~F}$ & $42 \pm 1.3 \mathrm{D}$ & $60 \pm 1.2 \mathrm{D}$ & $43 \pm 2.1 C$ & $58 \pm 1.4 \mathrm{~A}$ & $75 \pm 1.3 \mathrm{~B}$ & $43 \pm 2.3 B C$ & $52 \pm 1.2 \mathrm{C}$ & $81 \pm 4.1 \mathrm{~B}$ \\
\hline & LH Fermented & $21 \pm 0.7 F G$ & $37 \pm 1.1 \mathrm{EF}$ & $47 \pm 1.5 \mathrm{~F}$ & $53 \pm 2.8 \mathrm{~A}$ & $57 \pm 1.5 \mathrm{AB}$ & $70 \pm 1.5 \mathrm{C}$ & $18 \pm 1.6 \mathrm{~F}$ & $57 \pm 1.3 \mathrm{~B}$ & $79 \pm 1.7 \mathrm{~B}$ \\
\hline & LH Fermented Adj pH & $20 \pm 0.6 \mathrm{G}$ & $35 \pm 1.4 \mathrm{~F}$ & $51 \pm 1.6 \mathrm{~F}$ & $21 \pm 1.3 \mathrm{~F}$ & $42 \pm 1.2 \mathrm{E}$ & $72 \pm 3.5 B C$ & $44 \pm 1.9 \mathrm{BC}$ & $75 \pm 1.4 \mathrm{~A}$ & $90 \pm 3.6 \mathrm{~A}$ \\
\hline & BL Fermented & $22 \pm 0.3 F G$ & $37 \pm 1.7 \mathrm{EF}$ & $48 \pm 1.7 \mathrm{~F}$ & $55 \pm 1.5 \mathrm{~A}$ & $57 \pm 2.7 \mathrm{AB}$ & $70 \pm 3.6 \mathrm{C}$ & $28 \pm 1.5 \mathrm{E}$ & $60 \pm 1.1 B$ & $79 \pm 1.5 \mathrm{~B}$ \\
\hline & BL Fermented Adj pH & $20 \pm 0.7 \mathrm{G}$ & $38 \pm 1.9 \mathrm{E}$ & $56 \pm 2.8 \mathrm{E}$ & $48 \pm 1.3 \mathrm{~B}$ & $56 \pm 2.4 \mathrm{AB}$ & $80 \pm 3.1 \mathrm{~A}$ & $41 \pm 1.3 \mathrm{C}$ & $58 \pm 2.3 \mathrm{~B}$ & $88 \pm 2.1 \mathrm{~A}$ \\
\hline
\end{tabular}

$x_{ \pm}$Standard Error.

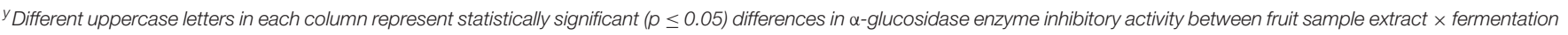
treatment interactions separately for each dilution and each fermentation time point.

managing glucose homeostasis, specifically during post-prandial stage is needed for improving glucose metabolism and preventing chronic hyperglycemia. Aqueous extracts of Bartlett pear and Kiowa blackberry showed significant anti-hyperglycemic functions in previous in vitro studies (Ankolekar et al., 2012a; Barbosa et al., 2013; Sarkar et al., 2015, 2016; Espe et al., 2019a). In this study, both fruit synergy and LAB-based fermentation were evaluated to determine anti-hyperglycemic properties of blackberry, pear, and blackberry: pear (30:70) combination.

Targeted in vitro inhibition of two critical enzymes involved in carbohydrate breakdowns and absorption of glucose in the bloodstream like $\alpha$-amylase and $\alpha$-glucosidase was evaluated to determine and reflect the anti-hyperglycemic functionalities of fermented and unfermented fruit extracts using appropriate rapid in vitro assay models. Moderate to high $\alpha$-glucosidase enzyme inhibitory activity was observed in undiluted sample of blackberry pear, and blackberry: pear (30:70) combination with and without LAB fermentation (Table 2). Statistically significant ( $p \leq 0.05$ ) differences in $\alpha$-glucosidase enzyme inhibitory activity between fruit sample extracts and fermentation treatments were also observed at all fermentation time points. Significant dose dependent response (1/5th, $1 / 2$, and undiluted) in $\alpha$-glucosidase enzyme inhibitory activity was also found across all samples. In Bartlett pear extracts (100\%) $\alpha$-glucosidase enzyme inhibitory activity decreased from 0 to $48 \mathrm{~h}$, while it gradually increased in pure Kiowa blackberry (100\%) extract. In blackberry: pear (30:70) combination, higher $\alpha$-glucosidase enzyme inhibitory activity was found at $24 \mathrm{~h}$ time point. At $0 \mathrm{~h}$ time point unfermented fruit extracts had significant $(p \leq 0.05)$ high $\alpha$-glucosidase enzyme inhibitory activity, while $B$. longum fermented and $\mathrm{pH}$ adjusted sample showed higher inhibitory activity at $48 \mathrm{~h}$ fermentation time point Therefore, fruit synergy retained significant $\alpha$-glucosidase enzyme inhibitory activity related antihyperglycemic functionality with or without LAB fermentation. Previously, Agustinah et al. (2016) reported high $\alpha$-glucosidase enzyme inhibitory activity in apple cider: blueberry combination.

These results indicated that improvement in $\alpha$-glucosidase enzyme inhibitory activity in blackberry and pear extract is independent of the $\mathrm{pH}$ of the sample. In a previous study, Kaprasob et al. (2019) found high $\alpha$-glucosidase enzyme inhibitory activity in B. longum fermented cashew apple extracts after $48 \mathrm{~h}$ fermentation.

Inhibitory activity of another key enzyme $\alpha$-amylase was also investigated to better understand the overall anti-hyperglycemic functionality of fermented and unfermented fruit extracts. Overall, very high $\alpha$-amylase enzyme inhibitory activity (90$100 \%$ ) was observed in undiluted sample of blackberry, pear, and blackberry: pear (30:70) combination (Table 3). The $\alpha$ amylase enzyme inhibitory activity (undiluted) of fermented and unfermented fruit sample extracts between different fermentation time points were not statistically significant. However, within each fermentation time point, $\alpha$-amylase enzyme inhibitory activity varied significantly $(p \leq 0.05)$ between fruit sample extracts and fermentation treatments. Due to such high baseline $\alpha$-amylase enzyme inhibitory activity, we also targeted $1 / 5$ th and $1 / 10$ th diluted samples. Even after 1/10th dilution, L. helveticus fermented fruit extracts (specifically in natural acidic $\mathrm{pH}$ ) had significantly higher $\alpha$-amylase enzyme inhibitory activity at $0 \mathrm{~h}$ time point. Fermentation with $B$. longum improved $\alpha$-amylase enzyme inhibitory activity in pure Kiowa blackberry extracts $(100 \%)$, which was more prominent in $1 / 5$ th diluted sample and at $48 \mathrm{~h}$ time point. High in vitro 
TABLE 3 | Anti-hyperglycemic property relevant $\alpha$-amylase enzyme inhibitory activity of (1/10th, 1/5th, and undiluted) Bartlett pear (100\%), 30:70 (blackberry: pear) combination, and Kiowa blackberry (100\%) extracts during (0, 24, and 48 h) fermentation with Lactobacillus helveticus (LH) and Bifidobacterium longum (BL).

\begin{tabular}{|c|c|c|c|c|c|c|c|c|c|c|}
\hline & & \multicolumn{3}{|c|}{$\mathrm{OH}$} & \multicolumn{3}{|c|}{$24 \mathrm{H}$} & \multicolumn{3}{|c|}{$48 \mathrm{H}$} \\
\hline & & 1/10 Dil & 1/5 Dil & Undil & 1/10 Dil & 1/5Dil & Undil & 1/10 Dil & 1/5 Dil & Undil \\
\hline \multirow[t]{5}{*}{ Pear $100 \%$} & Unfermented & $6 \pm 0.03^{x} \mathrm{GH}^{y}$ & $21 \pm 1.4 \mathrm{G}$ & $72 \pm 2.6 \mathrm{D}$ & $20 \pm 1.3$ & $47 \pm 3.2 \mathrm{E}$ & $80 \pm 3.9 \mathrm{C}$ & 0 & $10 \pm 0.04 \mathrm{~F}$ & $70 \pm 1.5 \mathrm{D}$ \\
\hline & LH Fermented & $57 \pm 2.3 \mathrm{~B}$ & $99 \pm 3.9 A$ & $100 \pm 2.5 \mathrm{~A}$ & $74 \pm 2.2$ & $100 \pm 0.9 A$ & $100 \pm 0.2 A$ & $17 \pm 0.5$ & $88 \pm 1.8 \mathrm{~A}$ & $100 \pm 1.7 \mathrm{~A}$ \\
\hline & LH Fermented Adjusted pH & $45 \pm 2.1 C$ & $100 \pm 4.4 \mathrm{~A}$ & $100 \pm 3.1 \mathrm{~A}$ & $80 \pm 2.5$ & $100 \pm 1.2 \mathrm{~A}$ & $100 \pm 0.2 \mathrm{~A}$ & $36 \pm 0.3$ & $87 \pm 4.1 \mathrm{~A}$ & $100 \pm 1.5 \mathrm{~A}$ \\
\hline & BL Fermented & $8 \pm 0.6 G$ & $30 \pm 2.1 \mathrm{EF}$ & $88 \pm 2.4 \mathrm{~B}$ & $85 \pm 1.6$ & $100 \pm 0.3 \mathrm{~A}$ & $100 \pm 0.5 \mathrm{~A}$ & 0 & $57 \pm 2.7 \mathrm{~B}$ & $100 \pm 1.7 \mathrm{~A}$ \\
\hline & BL Fermented Adjusted pH & $7 \pm 0.09 \mathrm{G}$ & $28 \pm 1.4 \mathrm{~F}$ & $81 \pm 5.1 C$ & $23 \pm 3.2$ & $80 \pm 0.5 B$ & $100 \pm 0.3 \mathrm{~A}$ & 0 & $20 \pm 0.8 \mathrm{E}$ & $80 \pm 1.3 C$ \\
\hline \multirow{5}{*}{$\begin{array}{l}\text { Blackberry: } \\
\text { Pear 30:70 }\end{array}$} & Unfermented & $8 \pm 0.02 G$ & $83 \pm 1.8 B$ & $100 \pm 1.5 \mathrm{~A}$ & 0 & $55 \pm 4.1 \mathrm{D}$ & $100 \pm 2.8 \mathrm{~A}$ & $8 \pm 0.6$ & $15 \pm 0.9 \mathrm{E}$ & $80 \pm 2.1 C$ \\
\hline & LH Fermented & $93 \pm 1.5 \mathrm{~A}$ & $99 \pm 3.5 \mathrm{~A}$ & $100 \pm 2.7 \mathrm{~A}$ & 0 & $68 \pm 3.2 \mathrm{C}$ & $100 \pm 2.3 \mathrm{~A}$ & $16 \pm 0.4$ & $60 \pm 3.6 \mathrm{~B}$ & $100 \pm 2.3 \mathrm{~A}$ \\
\hline & LH Fermented Adjusted pH & $41 \pm 2.5 \mathrm{CD}$ & $63 \pm 2.9 \mathrm{C}$ & $100 \pm 1.3 \mathrm{~A}$ & 0 & $57 \pm 3.6 \mathrm{D}$ & $100 \pm 2.2 \mathrm{~A}$ & $16 \pm 0.3$ & $42 \pm 3.2 \mathrm{C}$ & $90 \pm 3.9 B$ \\
\hline & BL Fermented & $6 \pm 0.3 \mathrm{GH}$ & $41 \pm 3.3 \mathrm{D}$ & $100 \pm 1.9 \mathrm{~A}$ & $10 \pm 0.6$ & $60 \pm 3.5 D$ & $100 \pm 2.6 \mathrm{~A}$ & 0 & $29 \pm 1.7 \mathrm{D}$ & $92 \pm 3.4 \mathrm{~B}$ \\
\hline & BL Fermented Adjusted pH & $1 \pm 0.08 \mathrm{H}$ & $21 \pm 1.6 \mathrm{G}$ & $100 \pm 1.6 \mathrm{~A}$ & $5 \pm 0.3$ & $40 \pm 3.1 F$ & $100 \pm 2.4 \mathrm{~A}$ & 0 & $16 \pm 0.8 \mathrm{E}$ & $90 \pm 2.5 B$ \\
\hline \multirow{5}{*}{$\begin{array}{l}\text { Blackberry } \\
100 \%\end{array}$} & Unfermented & $7 \pm 0.2 \mathrm{GH}$ & $28 \pm 1.4 \mathrm{~F}$ & $90 \pm 4.1 B$ & 0 & $14 \pm 0.8 \mathrm{G}$ & $90 \pm 4.5 B$ & $4 \pm 0.06$ & $57 \pm 1.4 \mathrm{~B}$ & $95 \pm 3.7 \mathrm{AB}$ \\
\hline & LH Fermented & $17 \pm 0.4 \mathrm{~F}$ & $86 \pm 1.3 \mathrm{~B}$ & $100 \pm 2.8 \mathrm{~A}$ & 0 & $15 \pm 1.3 \mathrm{G}$ & $66 \pm 3.2 \mathrm{D}$ & $1 \pm 0.02$ & $60 \pm 1.5 B$ & $100 \pm 2.9 \mathrm{~A}$ \\
\hline & LH Fermented Adjusted pH & $35 \pm 1.7 \mathrm{D}$ & $80 \pm 3.7 \mathrm{~B}$ & $100 \pm 2.5 \mathrm{~A}$ & 0 & $6 \pm 0.09 \mathrm{H}$ & $60 \pm 2.1 \mathrm{D}$ & $2 \pm 0.02$ & $17 \pm 0.6 \mathrm{E}$ & $100 \pm 2.1 \mathrm{~A}$ \\
\hline & BL Fermented & $25 \pm 0.8 \mathrm{E}$ & $35 \pm 2.5 \mathrm{DE}$ & $100 \pm 2.1 \mathrm{~A}$ & $16 \pm 1.3$ & $57 \pm 2.3 D$ & $100 \pm 2.5 \mathrm{~A}$ & $5 \pm 0.08$ & $93 \pm 0.9 A$ & $100 \pm 3.4 \mathrm{~A}$ \\
\hline & BL Fermented Adjusted pH & $14 \pm 0.5 F$ & $17 \pm 1.2 \mathrm{G}$ & $90 \pm 4.4 \mathrm{~B}$ & $3 \pm 0.08$ & $12 \pm 2.3 \mathrm{GH}$ & $80 \pm 2.3 C$ & $11 \pm 0.7$ & $27 \pm 1.2 \mathrm{D}$ & $100 \pm 2.6 \mathrm{~A}$ \\
\hline
\end{tabular}

$x_{ \pm}$Standard Error

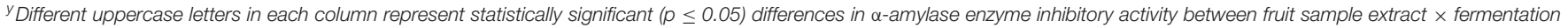
treatment interactions separately for each dilution and each fermentation time point.

$\alpha$-amylase enzyme inhibitory activity was previously reported in pear (Ankolekar et al., 2012a; Sarkar et al., 2015), blackberry (Sarkar et al., 2016), and blackberry: pear combinations (Warner, 2012). The high $\alpha$-amylase and moderate $\alpha$-glucosidase enzyme inhibitory activities of fermented and unfermented fruit extracts found in this study has significant relevance to target them in overall dietary support strategies for managing chronic hyperglycemia commonly associated with type 2 diabetes.

\section{Anti-hypertensive Functionality}

One way to control hypertension is by utilizing angiotensin-Iconverting enzyme (ACE) inhibiting compounds from natural or synthetic sources. Angiotensin-I-converting enzyme, converts inactive angiotensin I in the body into angiotensin II (Messerli et al., 2018). Angiotensin II stimulates the synthesis and release of aldosterone from the adrenal cortex, which then increases blood pressure via promoting sodium retention (Messerli et al., 2018). This is called the renin-angiotensin-aldosterone pathway, and it naturally helps regulate blood pressure. Utilizing natural ACE inhibitors from plant-based food sources are more attractive, due to the fact that most pharmaceutical drugs fully inhibit many other digestive enzymes as well as ACE and long-term use of synthetic ACE inhibitors can lead to renal dysfunction (Oussalah et al., 2020).

Previously, moderate in vitro ACE inhibitory activity was observed in aqueous extracts of Bartlett pear (Barbosa et al., 2013; Sarkar et al., 2015). In the current study, moderate to high ACE inhibitory activity was observed in pure Bartlett pear extracts (100\%), while pure Kiowa blackberry extracts had no inhibitory activity against ACE (Figure 3). Interestingly, integration of pear in blackberry resulted in low to moderate in vitro ACE inhibitory activity. Statistically significant differences in ACE inhibitory activity between fruit sample extracts and fermentation treatments were observed at all 3 fermentation time points. Fermented pear and blackberry: pear combination had higher ACE inhibitory activity at all fermentation time points, which was statistically significant $(p \leq 0.05)$ when compared to ACE inhibition by unfermented fruit sample extracts. Results of this study indicated that Bartlett pear is a compatible fruit target, which can be combined to improve anti-hypertensive property relevant ACE inhibitory activity in blackberry combined foods and beverages. Furthermore, LAB-based fermentation with $L$. helveticus can be used to improve ACE inhibitory potential of blackberry: pear fruit synergy and pure pear (Bartlett) extracts. Such improvement in ACE inhibitory activity has dietary and therapeutic relevance to address chronic hypertension, commonly associated with type 2 diabetes and other NCDs.

\section{Anti-bacterial Activity Against Helicobacter pylori}

Anti-bacterial activity of fermented fruit extracts were also investigated against human gut ulcer causing bacteria Helicobacter pylori. In this study, inhibition of $H$. pylori was only found with $B$. longum and $L$. helveticus fermented pure Kiowa blackberry (100\%) sample (Figure 4). No other sample inhibited the growth of $H$. pylori. Longer LAB fermentation up to $48 \mathrm{~h}$ resulted in greater $\mathrm{H}$. pylori zone of inhibition. The reason behind this inhibition is still not clear and $\mathrm{pH}$ was not the suspected cause, as all samples were $\mathrm{pH}$ adjusted prior to plating. Most phenolic compounds from plant-based food sources potentially prevent bacteria from utilizing proline dehydrogenase to obtain proline for energy needs and to understand this likely metabolic 


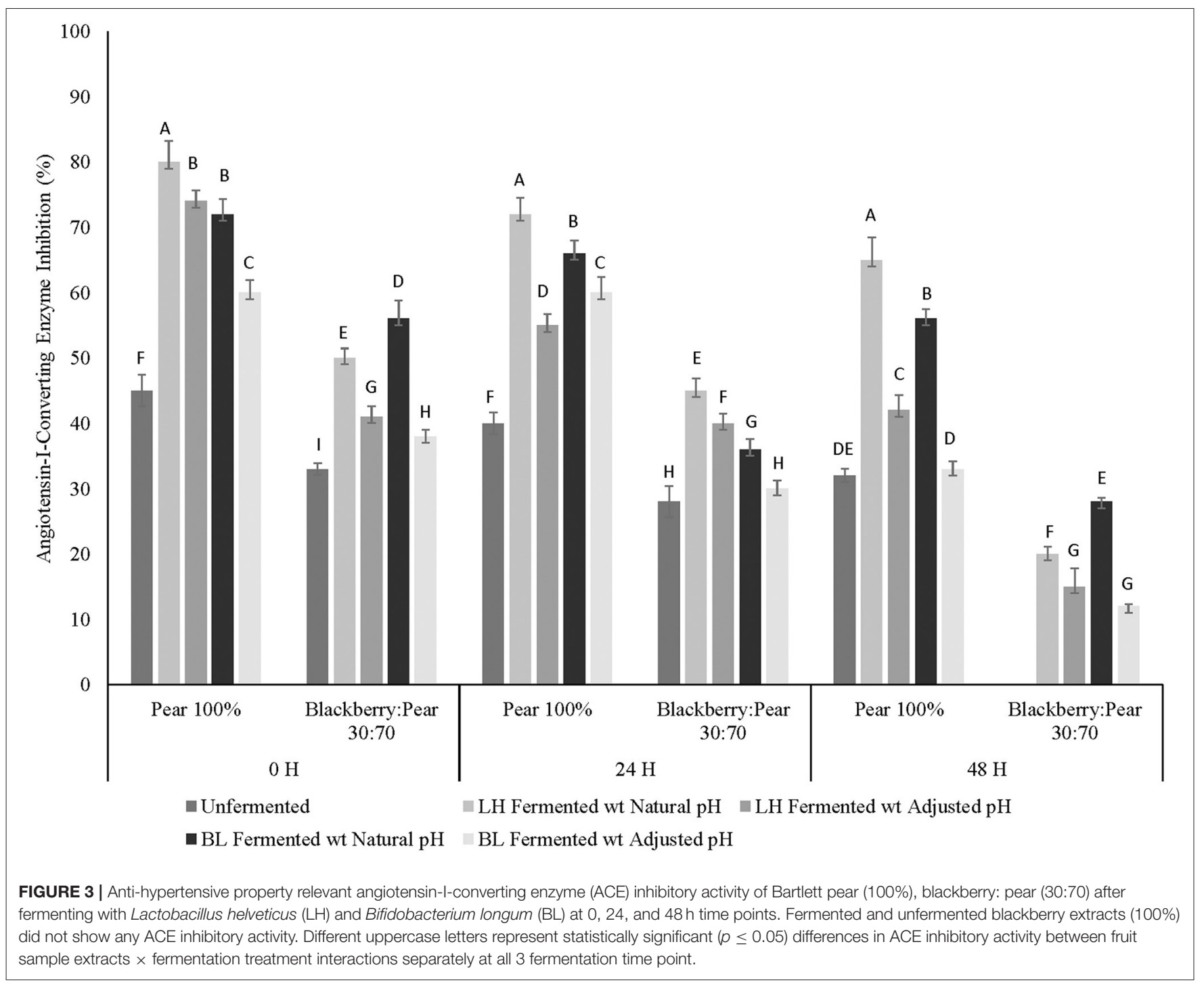

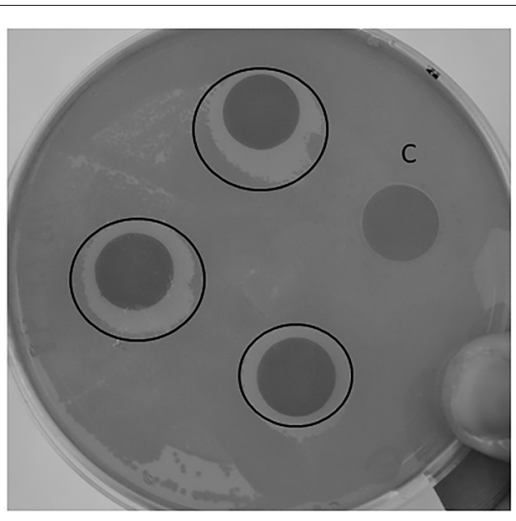

48 h LH Fermented 100\% blackberry

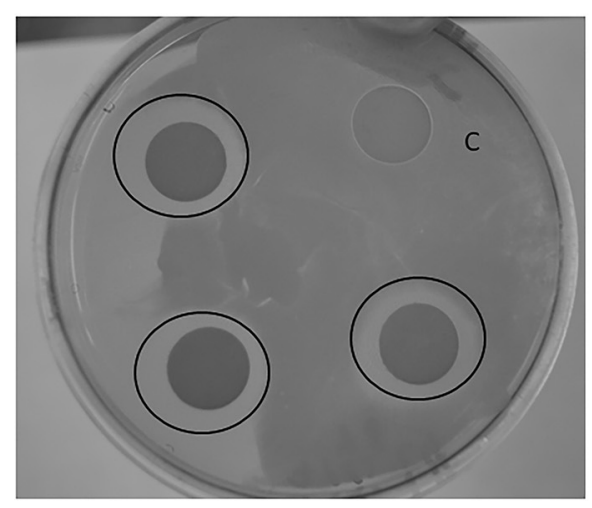

48 h BL Fermented $100 \%$ blackberry

FIGURE 4 | Disc diffusion assay-based Helicobacter pylori inhibition observed with $48 \mathrm{~h}$ LAB fermented (Lactobacillus helveticus and Bifidobacterium longum) Kiowa blackberry extracts (100\%). 
strategy, $H$. pylori was grown on plates containing proline to supplement the bacterial needs (Lin et al., 2005; Ankolekar et al., 2011). Even on these proline-enriched plates, the bacteria remained inhibited solely by fermented Kiowa blackberry extracts. Proline dehydrogenase inhibition is therefore ruled out as the reason for the inability of $H$. pylori to grow around $100 \%$ blackberry juice fermented with LAB. Previously, Goodman et al. (2020) observed H. pylori inhibitory activity in blackberry and raspberry extracts. Therefore, LAB-based fermentation can be recruited to improve antibacterial activity in berry derived foods and beverages, which has relevance in improving human gut health benefits in addition to its high antioxidant protective functions.

\section{CONCLUSION}

In this study, fruit synergy of blackberry and pear using 30:70 ratio resulted in higher phenolic-linked antioxidant and antihyperglycemic functionalities. Integration of pear in blackberry also resulted in anti-hypertensive property relevant ACE inhibitory activity in blackberry: pear (30:70) combination. Additionally, LAB-based fermentation, specifically $48 \mathrm{~h}$ fermentation with B. longum and L. helveticus further enhanced stability and retention of phenolic bioactives and associated functionalities such as antioxidant, anti-hyperglycemic, and anti-hypertensive properties in blackberry: pear (30:70) fruit synergy. Furthermore, LAB fermented Kiowa blackberry extracts showed anti-bacterial activity against $H$. pylori, which is relevant for managing gastric ulcer and stomach infections. Therefore, results of this study revealed that both health-targeted and

\section{REFERENCES}

Agustinah, W., Sarkar, D., Woods, F., and Shetty, K. (2016). Apple and blueberry synergies for designing bioactive ingredients for the management of early stages of type 2 diabetes. J. Food Qual. 39, 370-382. doi: 10.1111/jfq.12206

Ankolekar, C., Johnson, K., Pinto, M., Johnson, D., Labbe, R. G., Greene, D., et al. (2012b). Fermentation of whole apple juice using Lactobacillus acidophilus for potential dietary management of hyperglycemia, hypertension, and modulation of beneficial bacterial responses. J. Food Biochem. 36, 718-738. doi: 10.1111/j.1745-4514.2011.00596.x

Ankolekar, C., Pinto, M., Greene, D., and Shetty, K. (2011). Phenolic bioactive modulation by Lactobacillus acidophilus mediated fermentation of cherry extracts for anti-diabetic functionality, Helicobacter pylori inhibition and probiotic Bifidobacterium longum stimulation. Food Biotechnol. 25, 305-335. doi: $10.1080 / 08905436.2011 .617255$

Ankolekar, C., Pinto, M., Greene, D., and Shetty, K. (2012a). In vitro bioassay based screening of antihyperglycemia and antihypertensive activities of Lactobacillus acidophilus fermented pear juice. Innov. Food Sci. Emerg. Technol. 13, 221-230. doi: 10.1016/j.ifset.2011.10.008

Apostolidis, E., Kwon, Y. I., Ghaedian, R., and Shetty, K. (2007). Fermentation of milk and soymilk by Lactobacillus bulgaricus and Lactobacillus acidophilus enhances functionality for potential dietary management of hyperglycemia and hypertension. Food Biotechnol. 21, 217-236. doi: 10.1080/08905430701 534032

Bacchetti, T., Turco, I., Urbano, A., Morresi, C., and Ferretti, G. (2019). Relationship of fruit and vegetable intake to dietary antioxidant capacity and markers of oxidative stress: a sex-related study. Nutrition 61, 164-172. doi: 10.1016/j.nut.2018.10.034 compatible fruit synergy and LAB-based fermentation are effective bioprocessing tools for improving antioxidant, antihyperglycemic, anti-hypertensive, and antibacterial properties of blackberry and pear fruit synergy, which can be integrated in dietary support strategies aligning needs of early stages of type 2 diabetes. Such improved redox-linked antioxidant and antibacterial function is also pertinent for reducing post-harvest spoilage and improving keeping quality of nutritionally relevant bioactive rich fruits and beverages derived from blackberry: pear fruit synergy.

\section{DATA AVAILABILITY STATEMENT}

The raw data supporting the conclusions of this article will be made available by the authors, without undue reservation.

\section{AUTHOR CONTRIBUTIONS}

NP, DS, and KS: conceptualization, writing - original draft, and investigation. NP and DS: data curation and formal analysis. KS, RL, and CK: methodology. NP, DS, RL, and KS: project administration. KS, RL, DS, and CK: writing-review and editing. All authors contributed to the article and approved the submitted version.

\section{ACKNOWLEDGMENTS}

We wish to thank the Dr. Floyd Woods of Auburn University (AL, USA) for providing Kiowa blackberry sample for this research.

Barbosa, A. C. L., Sarkar, D., Pinto, M. D. S., Ankolekar, C., Greene, D., and Shetty, K. (2013). Type 2 diabetes relevant bioactive potential of freshly harvested and long-term stored pears using in vitro assay models. J. Food Biochem. 37, 677-686. doi: 10.1111/j.1745-4514.2012.00665.x

Cheplick, S., Kwon, Y. I., Bhowmik, P., and Shetty, K. (2007). Clonal variation in raspberry fruit phenolics and relevance for diabetes and hypertension management. J. Food Biochem. 31, 656-679. doi: 10.1111/j.1745-4514.2007.00136.x

Cheplick, S., Kwon, Y. I., Bhowmik, P., and Shetty, K. (2010). Phenoliclinked variation in strawberry cultivars for potential dietary management of hyperglycemia and related complications of hypertension. Bioresour. Technol. 101, 404-413. doi: 10.1016/j.biortech.2009.07.068

Cheplick, S., Sarkar, D., Bhowmik, P., and Shetty, K. (2015). Phenolic bioactives from developmental stages of highbush blueberry (Vaccinium corymbosum) for hyperglycemia management using in vitro models. Can. J. Plant Sci. 95, 653-662. doi: 10.4141/cjps-2014-352

Cheplick, S., Sarkar, D., Bhowmik, P. C., and Shetty, K. (2017). Improved resilience and metabolic response of transplanted blackberry plugs using chitosan oligosaccharide elicitor treatment. Can. J. Plant Sci. 98, 717-731. doi: 10.1139/cjps-2017-0055

Curiel, J. A., Pinto, D., Marzani, B., Filannino, P., Farris, G. A., Gobbetti, M., et al. (2015). Lactic acid fermentation as a tool to enhance the antioxidant properties of Myrtus communis berries. Microb. Cell Fact. 14, 1-10. doi: 10.1186/s12934-015-0250-4

da Silva Pinto, M., Lajolo, F. M., and Genovese, M. I. (2008). Bioactive compounds and quantification of total ellagic acid in strawberries (Fragaria $x$ ananassa Duch.). Food Chem. Sci. Rep. 107, 1629-1635. doi: $10.1016 /$ j.foodchem.2007.10.038 
Darfour-Oduro, S. A., Buchner, D. M., Andrade, J. E., and Grigsby-Toussaint, D. S. (2018). A comparative study of fruit and vegetable consumption and physical activity among adolescents in 49 Low-and-Middle-Income Countries. Sci. Rep. 8, 1-12. doi: 10.1038/s41598-018-19956-0

de Souza, V. R., Pereira, P. A. P., Teixeira, T. R., Silva, T. L. T. D., Pio, R., and Queiroz, F. (2015). Influence of processing on the antioxidant capacity and bioactive compounds in jellies from different blackberry cultivars. Int. J. Food Sci. Tech. 50, 1658-1665. doi: 10.1111/ijfs. 12819

Espe, A., Sarkar, D., Hatterman-Valenti, H., and Shetty, K. (2019a). Phenolic bioactive-linked antioxidant, and anti-hyperglycemic functionalities of blackberry (Rubus sp.) from two different maturation stages. Acta Hortic. 1277, 495-504. doi: 10.17660/ActaHortic.2020.1277.70

Espe, A., Sarkar, D., Hatterman-Valenti, H., and Shetty, K. (2019b). Screening of blackberry cultivars for phenolic bioactive-linked antioxidant and anti-hyperglycemic properties. Acta Hortic. 1277, 505-513. doi: 10.17660/ActaHortic.2020.1277.71

Fujita, A., Sarkar, D., Genovese, M. I., and Shetty, K. (2017). Improving antihyperglycemic and anti-hypertensive properties of camu-camu (Myriciaria dubia Mc. Vaugh) using lactic acid bacterial fermentation. Process Biochem. 59, 133-140. doi: 10.1016/j.procbio.2017.05.017

Goodman, C., Lyon, K., Scotto, A., Roe, M. M., Moghimpour, F., Sebrell, T. A., et al. (2020). A high-throughput metabolic microarray assay reveals antibacterial effects of black and red raspberries and blackberries against Helicobacter pylori infection. bioRxiv. doi: 10.1101/2020.12.14.422663

Gowd, V., Bao, T., and Chen, W. (2019). Antioxidant potential and phenolic profile of blackberry anthocyanin extract followed by human gut microbiota fermentation. Food Res. Int. 120, 523-533. doi: 10.1016/j.foodres.2018. 11.001

Gunathilake, K. D. P. P., Rupasinghe, H. V., and Pitts, N. L. (2013). Formulation and characterization of a bioactive-enriched fruit beverage designed for cardio-protection. Food Res. Int. 52, 535-541. doi: 10.1016/j.foodres.2013. 02.051

Huynh, N. K., Wilson, M. D., Eyles, A., and Stanley, R. A. (2019). Recent advances in postharvest technologies to extend the shelf life of blueberries (Vaccinium sp.), raspberries (Rubus idaeus L.) and blackberries (Rubus sp.). J. Berry Res. 9, 687-707. 10.3233/JBR-190421 doi: 10.3233/JBR-190421

Kaprasob, R., Kerdchoechuen, O., Laohakunjit, N., Sarkar, D., and Shetty, K. (2017). Fermentation-based biotransformation of bioactive phenolics and volatile compounds from cashew apple juice by select lactic acid bacteria. Process Biochem. 59, 141-149. doi: 10.1016/j.procbio.2017. 05.019

Kaprasob, R., Sarkar, D., Kerdchoechuen, O., Laohakunjit, N., Khanongnuch, C., and Shetty, K. (2019). Beneficial lactic acid bacteria-based bioprocessing of cashew apple juice for targeting antioxidant nutraceutical inhibitors as relevant antidotes to type 2 diabetes. Process Biochem. 82, 40-50. doi: 10.1016/j.procbio.2019.05.005

Liao, X., Greenspan, P., Srivastava, A., and Pegg, R. B. (2020). Characterizing the phenolic constituents of US Southeastern blackberry cultivars. J. Berry Res. 10, 311-327. 10.3233/JBR-190475 doi: 10.3233/JBR-190475

Lin, Y. T., Vattem, D., Labbe, R. G., and Shetty, K. (2005). Enhancement of antioxidant activity and inhibition of Helicobacter pylori by phenolic phytochemical-enriched alcoholic beverages. Process Biochem. 40, 2059-2065. doi: 10.1016/j.procbio.2004.07.019

Liu, C. F., and Pan, T. M. (2010). In vitro effects of lactic acid bacteria on cancer cell viability and antioxidant activity. J. Food Drug Anal. 18, 77-86. doi: 10.38212/2224-6614.2287

Lynch, K. M., Zannini, E., Coffey, A., and Arendt, E. K. (2018). Lactic acid bacteria exopolysaccharides in foods and beverages: isolation, properties, characterization, and health benefits. Annu. Rev. Food Sci. Technol. 9, 155-176. doi: 10.1146/annurev-food-030117-012537

McCue, P., Kwon, Y. I., and Shetty, K. (2005). Anti-amylase, anti-glucosidase and anti-angiotensin i-converting enzyme potential of selected foods. J. Food Biochem. 29, 278-294. doi: 10.1111/j.1745-4514.2005.00020.x

Messerli, F. H., Bangalore, S., Bavishi, C., and Rimoldi, S. F. (2018). Angiotensinconverting enzyme inhibitors in hypertension: to use or not to use? J. Am. Coll. Cardiol. 71, 1474-1482. doi: 10.1016/j.jacc.2018.01.058

Michalska, A., and Łysiak, G. (2015). Bioactive compounds of blueberries: postharvest factors influencing the nutritional value of products. Int. J. Mol. Sci. 16, 18642-18663. doi: 10.3390/ijms160818642
Nediani, C., and Giovannelli, L. (2020). Oxidative stress and inflammation as targets for novel preventive and therapeutic approaches in non-communicable diseases. Antioxidants 9:290. doi: 10.3390/antiox 9040290

Oussalah, A., Gleye, S., Clerc Urmes, I., Laugel, E., Callet, J., Barbé, F., et al. (2020). Long-term ACE Inhibitor/ARB use is associated with severe renal dysfunction and acute kidney injury in patients with severe COVID-19: results from a referral center cohort in the northeast of France. Clin. Infect. Dis. 71, 2447-2456. doi: 10.1093/cid/ciaa677

Park, J. B., Lim, S. H., Sim, H. S., Park, J. H., Kwon, H. J., Nam, H. S., et al. (2017). Changes in antioxidant activities and volatile compounds of mixed berry juice through fermentation by lactic acid bacteria. Food Sci. Biotech. 26, 441-446. doi 10.1007/s10068-017-0060-z

Ryu, J. Y., Kang, H. R., and Cho, S. K. (2019). Changes over the fermentation period in phenolic compounds and antioxidant and anticancer activities of blueberries fermented by Lactobacillus plantarum. J. Food Sci. 84, 2347-2356. doi: 10.1111/1750-3841.14731

Sarkar, D., Agustinah, W., Woods, F., Coneva, E., Vinson, E., and Shetty, K. (2017). In vitro screening and evaluation of phenolic antioxidant-linked antihyperglycemic functions of rabbit-eye blueberry (Vaccinium ashei) cultivars. J. Berry Res. 7, 163-177. doi: 10.3233/JBR-170154

Sarkar, D., Ankolekar, C., Pinto, M., and Shetty, K. (2015). Dietary functional benefits of Bartlett and Starkrimson pears for potential management of hyperglycemia, hypertension and ulcer bacteria Helicobacter pylori while supporting beneficial probiotic bacterial response. Food Res. Int. 69, 80-90. doi: 10.1016/j.foodres.2014.12.014

Sarkar, D., Orwat, J., Hurburt, T., Woods, F., Pitts, J. A., and Shetty, K. (2016). Evaluation of phenolic bioactive-linked functionality of blackberry cultivars targeting dietary management of early stages type-2 diabetes using in vitro models. Sci. Hortic. 212, 193-202. doi: 10.1016/j.scienta.2016.10.003

Sarkar, D., and Shetty, K. (2014). Metabolic stimulation of plant phenolics for food preservation and health. Annu. Rev. Food Sci. Technol. 5, 395-413. doi: 10.1146/annurev-food-030713-092418

Satija, A., and Hu, F. B. (2018). Plant-based diets and cardiovascular health. Trends Cardiovasc. Med. 28, 437-441. doi: 10.1016/j.tcm.2018.02.004

Schulz, M., Seraglio, S. K. T., Della Betta, F., Nehring, P., Valese, A. C., Daguer, H., et al. (2019). Blackberry (Rubus ulmifolius Schott): Chemical composition, phenolic compounds and antioxidant capacity in two edible stages. Food Res. Int. 122, 627-634. doi: 10.1016/j.foodres.2019.01.034

Shetty, K., Curtis, O. F., Levin, R. E., Witkowsky, R., and Ang, W. (1995). Prevention of vitrification asociated with in vitro shoot culture of Oregano.(Origanum vulgare) by Pseudomonas spp. J. Plant Physiol. 147, 447451. doi: 10.1016/S0176-1617(11)82181-4

Shetty, K., and Wahlqvist, M. (2004). A model for the role of the prolinelinked pentose-phosphate pathway in phenolic phytochemical biosynthesis and mechanism of action for human health and environmental applications. Asia Pac. J. Clin. Nutr. 13, 1-24.

Skrovankova, S., Sumczynski, D., Mlcek, J., Jurikova, T., and Sochor, J. (2015). Bioactive compounds and antioxidant activity in different types of berries. Int. J. Mol. Sci. 16, 24673-24706. doi: 10.3390/ijms161024673

Stevenson, T. H., Bauer, N., Lucia, L. M., and Acuff, G. R. (2000). Attempts to isolate Helicobacter from cattle and survival of Helicobacter pylori in beef products. J. Food Prot. 63, 174-178. doi: 10.4315/0362-028X-63.2.174

Su, D., Zhang, R., Hou, F., Zhang, M., Guo, J., Huang, F., et al. (2014). Comparison of the free and bound phenolic profiles and cellular antioxidant activities of litchi pulp extracts from different solvents. BMC Complement. Altern. Med. 14, 1-10. doi: 10.1186/1472-6882-14-9

Warner, S. D. (2012). Evaluation of blackberry cultivars and blackberry-pear synergies for potential management of type ii diabetes and hypertension (Master Theses). Department of Food Sciences, University of Massachusetts, Amherst, MA.

Willems, J. L., and Low, N. H. (2018). Structural identification of compounds for use in the detection of juice-to-juice debasing between apple and pear juices. Food Chem. 241, 346-352. doi: 10.1016/j.foodchem.2017. 08.104

Xiao, J., and Bai, W. (2019). Bioactive phytochemicals. Crit. Rev. Food Sci. Nutr. 59, 827-829. doi: 10.1080/10408398.2019.1601848

Conflict of Interest: The authors declare that the research was conducted in the absence of any commercial or financial 
relationships that could be construed as a potential conflict of interest.

Publisher's Note: All claims expressed in this article are solely those of the authors and do not necessarily represent those of their affiliated organizations, or those of the publisher, the editors and the reviewers. Any product that may be evaluated in this article, or claim that may be made by its manufacturer, is not guaranteed or endorsed by the publisher.
Copyright (C) 2021 Pucel, Sarkar, Labbe, Khanongnuch and Shetty. This is an open-access article distributed under the terms of the Creative Commons Attribution License (CC BY). The use, distribution or reproduction in other forums is permitted, provided the original author(s) and the copyright owner(s) are credited and that the original publication in this journal is cited, in accordance with accepted academic practice. No use, distribution or reproduction is permitted which does not comply with these terms. 